Article

\title{
An Efficient Photocatalyst for Fast Reduction of Cr(VI) by Ultra-Trace Silver Enhanced Titania in Aqueous Solution
}

\author{
Shengyan Pu ${ }^{1,2}, * \mathbb{D}$, Yaqi Hou ${ }^{1}$, Hongyu Chen ${ }^{1}$, Daili Deng ${ }^{1}$, Zeng Yang ${ }^{1}$, Shengyang Xue ${ }^{1}$, \\ Rongxin $\mathrm{Zhu}^{1}{ }^{1}$, Zenghui Diao ${ }^{2,3}$ and Wei Chu ${ }^{2}$ \\ 1 State Key Laboratory of Geohazard Prevention and Geoenvironment Protection, Chengdu University of \\ Technology, Chengdu 610059, China; houyaqilove@gmail.com (Y.H.); chenhongyu98@163.com (H.C.); \\ dengdaili.1022@gmail.com (D.D.); yangzeng199529@gmail.com (Z.Y.); shengyangxue@gmail.com (S.X.); \\ rongxinzhu@outlook.com (R.Z.) \\ 2 Department of Civil and Environment Engineering, The Hong Kong Polytechnic University, Hong Kong, \\ China; zenghuid86@scsio.ac.cn (Z.D.); wei.chu@polyu.edu.hk (W.C.) \\ 3 School of Environmental Science and Engineering, Zhongkai University of Agriculture and Engineering, \\ Guangzhou 510225, China \\ * Corresponding: pushengyan@gmail.com or pushengyan13@cdut.cn; Tel./Fax: +86-(0)-28-8407-3253
}

Received: 10 May 2018; Accepted: 14 June 2018; Published: 19 June 2018

\begin{abstract}
For the purpose of establishing a simple route to prepare a metal-semiconductor hybrid catalyst efficiently and reduce its cost through precise doping noble metals. In this study, ultra-trace silver doped $\mathrm{TiO}_{2}$ photocatalysts were fabricated via a "green" ultrasonic impregnation-assisted photoreduction strategy in an ethanol system, and its photocatalytic performance was systematically investigated by utilizing $\mathrm{Cr}(\mathrm{VI})$ as the model contaminant. A schottky energy barrier was constructed in $\mathrm{Ag} @ \mathrm{TiO}_{2}$, which served as a recombination center and possessed superior photocatalytic activity for $\mathrm{Cr}(\mathrm{VI})$ reduction. The obtained catalysts exhibited a significant $e^{-} / h^{+}$separation efficiency which directly led to an obvious photocatalytic property enhancement. Then, the resultant $\mathrm{Ag} @ \mathrm{TiO}_{2}(0.06 \mathrm{wt}$ $\%, 30$ min irradiation) showed about 2.5 times the activity as that of commercial P25 NPs for Cr(VI) degradation. Moreover, after five cycles, it still maintained considerably high catalytic ability (62\%). This work provides a deep insight into preparation techniques of metal-semiconductor photocatalyst and broadens their application prospect.
\end{abstract}

Keywords: $\mathrm{Ag} @ \mathrm{TiO}_{2} ; \mathrm{Cr}(\mathrm{VI})$ reduction; in-situ photoreduction; ultrasonic impregnation; ultra-trace silver

\section{Introduction}

Nowadays, heavy metals pollution in aquatic environments poses serious risks to public health and ecological systems since the rapid development of industrialization [1]. As a non-degradable and toxic metal ion, $\mathrm{Cr}(\mathrm{VI})$ has been commonly identified in aquatic circumstances, due to its carcinogenic, mutagenic and teratogenic effects on living creatures [2]. The Ministry of Ecology and Environment of the People's Republic of China and World Health Organization (WHO) have regulated the maximum concentration authorized in drinking water as being below $0.05 \mathrm{mg} / \mathrm{L}$ (Sanitary Standard for Drinking Water Quality (2001)) [3,4]. However, the inevitable drawbacks of high cost or secondary contamination still exist among conventional methods to remove heavy metals from aqueous solutions, such as chemical reduction [5,6], membrane separation [7], electrolytic [8], ferrite method [9,10], precipitation [11], adsorption [12,13], ion exchange [14] and biological method [15]. Hence, it is important to explore a cost-efficient method for $\mathrm{Cr}(\mathrm{VI})$ removal. 
Heterogeneous photocatalysis is achieved by the excitation of electrons from semiconductors' valence band $(\mathrm{VB})$ to the conduction band $(\mathrm{CB})$ upon light irradiation, wherein the excited electrons and holes can be directly applied in redox processes. Owing to the highly reductive property of photo-generated electrons, photocatalysis [16] can be served as a desirable reductive. Compared to the conventional methods, it has relatively broader application prospects due to its recyclable and non-secondary pollution advantages [17]. For example, reduced graphene oxide and $\mathrm{ZnO}$ hybrids ( $\mathrm{RGO} / \mathrm{ZnO}$ ) was utilized in different particle sizes for photocatalytic reduction of $\mathrm{Cr}(\mathrm{VI})$ [18]. In parallel, the photocatalytic $\mathrm{Pb}(\mathrm{II})$ reduction over $\mathrm{WO}_{3} / \mathrm{TiO}_{2}$ nanomaterials, the reduction capacity was increased from $52.2 \%$ to $74.7 \%$ via $\mathrm{WO}_{3}$ doping [19]. Moreover, The photocatalytic removal of heavy metal ions by $\mathrm{TiO}_{2}$ nanotubes could be further enhanced through $\mathrm{Cu}^{2+}$ loadings [20].

Furthermore, to improve the semiconductors' catalytic performance [21], the noble metal deposition [22] recently has been proven to be a predominant way to heighten the activity of photocatalysis by creating the Schottky barrier at the semiconductor metal interface, which helps in separating the photo-excited electrons in the CB onto the metal nanoparticles (NPs) [23]. During the past decade, various noble metals such as $\mathrm{Pt}, \mathrm{Au}$, and $\mathrm{Ag}$ have been frequently immobilized on $\mathrm{TiO}_{2}[24,25]$ or other semiconductors to enhance their photocatalytic performance. However, among a wide variety of metal-semiconductor hetero-structures [26], $\mathrm{Ag} @ \mathrm{TiO}_{2}$ [27] photocatalysts aroused tremendous attention as they showed the most efficient plasmon resonance which was favorable for catalytic enhancement [28]. Therefore, various methods to obtain $\mathrm{Ag} @ \mathrm{TiO}_{2}$ composites have been developed, such as hydrothermal [29], sol-gel [30], magnetron co-sputtering [31], photodeposition [32], sedimentation and impregnation [33]. These methods are usually either complex or require rather extreme conditions to operate. To obtain an efficient $\mathrm{Ag} @ \mathrm{TiO}_{2}$ photocatalyst, the silver dosage is still relatively high ( $>1 \mathrm{wt} \%)$, which greatly elevates its cost and limits its actual application. For instance, Chen and Zhang [30] synthesized an $\mathrm{Ag} @ \mathrm{TiO}_{2}$ compound through a novel one-pot sol-gel strategy with $3.9 \mathrm{wt} \%$ silver addition and systematically studied its potent antibacterial activities. Liu et al. [34] demonstrated the deposition of $\mathrm{Ag}$ nanoparticles on $\mathrm{TiO}_{2}$ nanofibers with $4.65 \mathrm{wt} \%$ silver dosage by a facile polyol synthesis, and the result showed superior natural antibacterial activity and high-performance photocatalytic disinfection under solar irradiation. Considering the conventional complex procedures and high silver consumption in $\mathrm{Ag} @ \mathrm{TiO}_{2}$ preparation, how to simplify the fabrication steps and control the silver doping amount would be the crucial steps to control the cost and broaden the practical application of $\mathrm{Ag} @ \mathrm{TiO}_{2}$. Particularly, how to obtain an efficient catalyst under an ultra-trace noble metal deposition.

In this work, a facile photoreduction strategy was utilized to in situ synthesize $\mathrm{Ag} @ \mathrm{TiO}_{2}$ photocatalysts with ultra and exhibited superior photocatalytic activity on reducing highly toxic $\mathrm{Cr}(\mathrm{VI})$ to low-toxic $\mathrm{Cr}(\mathrm{III})$. The photoreduction properties of $\mathrm{Ag} @ \mathrm{TiO}_{2}$ were evaluated in different influencing parameters, such as the amount of $\mathrm{Ag}$, the initial $\mathrm{pH}$ of solution, the amount of catalyst dosage, the light intensity and the coexisting ions. The results shown that the synthesized $\mathrm{Ag} @ \mathrm{TiO}_{2}$ bears good $\mathrm{Cr}(\mathrm{VI})$ reduction performance, which provides a deep insight for the application of photocatalysis in wastewater treatment.

\section{Results and Discussion}

\subsection{Preparation and Characterizations of Ultra-Trace Silver Enhanced Titania Photocatalyst}

The ultra-trace silver doped $\mathrm{TiO}_{2}$ photocatalysts were prepared via a "green" ultrasonic impregnation assisted photoreduction strategy, as shown in Figure 1. Firstly, the color of ethanol and $\mathrm{TiO}_{2}$ mixture maintained no change under dark conditions after $\mathrm{AgNO}_{3}$ addition. During the illuminated period, the mixture's color gradually turned from initial ecru to light blue (the color of products gradually deepened with the Ag dosage increasing, such as yellow-brown, purple-brown, etc., which mainly due to the photogenerated electrons $\left(e^{-}\right)$assisted $\mathrm{Ag}^{+}$reduction process (Figure 1a). 
Then, the obtained catalysts were used for $\mathrm{Cr}(\mathrm{VI})$ reduction (Figure $1 \mathrm{~b}) . \mathrm{Cr}(\mathrm{VI})$ was first adsorbed on the surface of $\mathrm{Ag} @ \mathrm{TiO}_{2}$, and then $\mathrm{Cr}(\mathrm{VI})$ was reduced to $\mathrm{Cr}(\mathrm{III})$ gradually by the $\mathrm{CB}$ formed $e^{-}$.

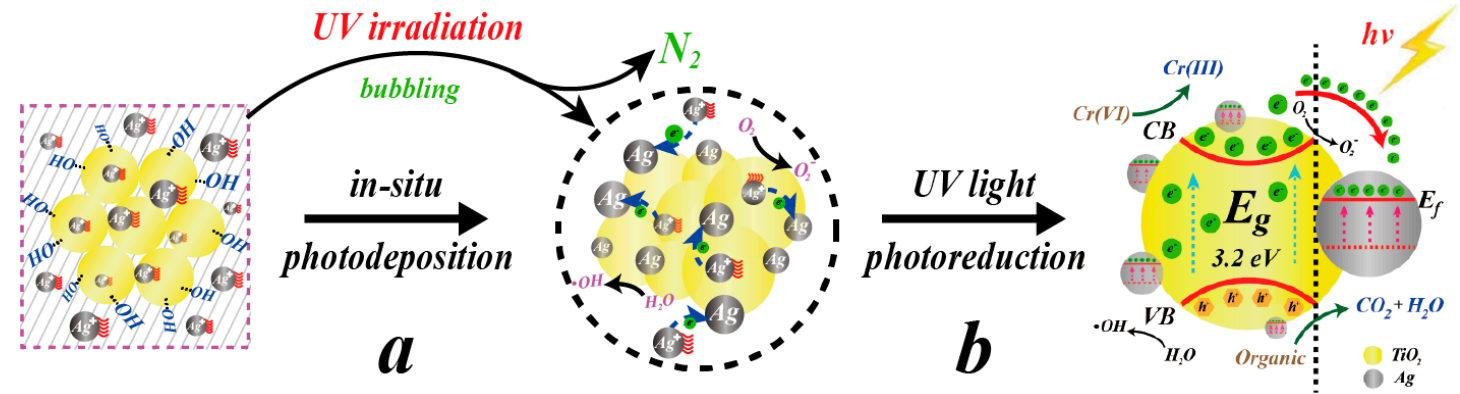

Figure 1. Schematic illustration of (a) synthesis of ultra-trace silver doped $\mathrm{TiO}_{2}$ composites via ultrasonic impregnation assisted deposition through an in situ UV-assisted photoreduction strategy; (b) photoreduction of highly toxic $\mathrm{Cr}(\mathrm{VI})$ to nontoxic $\mathrm{Cr}(\mathrm{III})$ by resultant $\mathrm{Ag} @ \mathrm{TiO}_{2}$ photocatalysts under UV irradiation.

Figure 2a shows the typical morphology and surface composition of the resultant $\mathrm{Ag} @ \mathrm{TiO}_{2}$ compound. The transmission electron microscope (TEM) image clearly shows the sphere-like synthesized material with an average diameter of ca. $24.5 \pm 2 \mathrm{~nm}$. High resolution transmission electron microscope (HRTEM, Figure $2 b$ ) observation revealed that $\mathrm{TiO}_{2}$ nanoparticles crystallized well with a lattice fringes spacing of $0.35 \mathrm{~nm}$, which well matches the $d$-spacing of (111) plane of $\mathrm{TiO}_{2}$ $(d=0.35 \mathrm{~nm})$. Furthermore, the $d$-spacing of $0.235 \mathrm{~nm}$ could be found either which fits the (001) plane $d$ spacing of $\mathrm{TiO}_{2}(d=0.235 \mathrm{~nm})$ and no obvious Ag nanoparticles could be found since the rather trace silver addition of $0.06 \mathrm{wt} \%$. However, as shown in Figure S1 and Table 1, silver nanoparticles exist on the surface of $\mathrm{TiO}_{2}$. According to the BET surface area analysis (Tables S1 and S2), the Ag doping ratio and $h^{+}$scavenger (ethanol) concentration do not influence the specific surface area of $\mathrm{Ag} @ \mathrm{TiO}_{2}$ obviously.

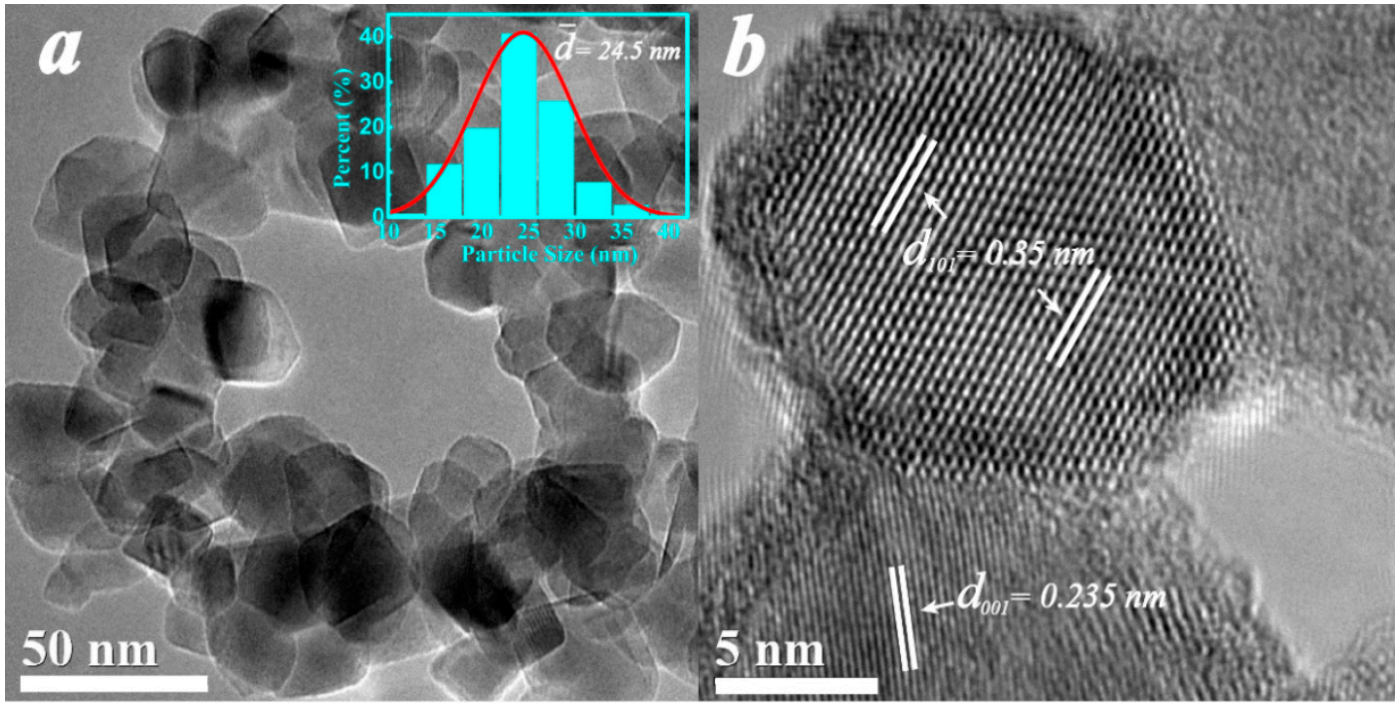

Figure 2. (a) TEM image of $\mathrm{Ag} @ \mathrm{TiO}_{2}(0.06 \mathrm{wt} \%, 30 \mathrm{~min}$ radiation) and NPs size distribution graphic (obtained by counting $114 \mathrm{Ag} @ \mathrm{TiO}_{2}$ particles); (b) HRTEM images of the prepared $\mathrm{Ag} @ \mathrm{TiO}_{2}$ composites, $\mathrm{d}_{001}=0.235 \mathrm{~nm}, \mathrm{~d}_{101}=0.35 \mathrm{~nm}$. 
Table 1. ICP-AES date of Ag@ $\mathrm{TiO}_{2}$.

\begin{tabular}{ccccccc}
\hline Mass/g & Volume/mL & Dilution Factor & Element & Readings mg/L & Conversion $\mathbf{~ m g} / \mathbf{k g}$ & $\mathbf{A g} / \mathrm{TiO}_{\mathbf{2}} \mathbf{~ w t} \%$ \\
\hline \multirow{2}{*}{0.0164} & \multirow{2}{*}{50} & 1 & $\mathrm{Ag}$ & 0.1778 & 542.03 & \multirow{2}{*}{0.0648} \\
& & 50 & $\mathrm{Ti}$ & 3.2883 & 501260.67 & \\
\hline
\end{tabular}

Considering the mild experimental conditions, the obtained nanocompounds exhibited similar X-ray diffraction (XRD) patterns to the pure $\mathrm{TiO}_{2}$, as shown in Figure 3 and Figure S2. Specifically, the peaks of $\mathrm{Ag} @ \mathrm{TiO}_{2}$ at $2 \theta$ values of $25.1^{\circ}, 37.6^{\circ}, 47.9^{\circ}, 53.7^{\circ}, 55.1^{\circ}, 62.6^{\circ}, 68.8^{\circ}, 70.1^{\circ}$, and $75.0^{\circ} \mathrm{might}$ belong to (101), (004), (200), (105), (211), (204), (116), (220), and (215) crystal planes of anatase phase (JCPDS Card No. 21-1272), respectively. Moreover, the peaks at $27.4^{\circ}$ and $36.0^{\circ}$ were ascribed to the (110) and (101) planes of rutile phase (JCPDS Card No. 21-1276). In comparison to bare $\mathrm{TiO}_{2}$, the peaks at $2 \theta$ value of $38.1^{\circ}, 44.23^{\circ}, 64.4^{\circ}$, and $77.4^{\circ}$ could be found, which belong to the (111), (200), (220), and (311) planes of Ag (JCPDS card number: 04-0783), respectively. However, since the Ag addition was rather low and overlapping by the $\mathrm{TiO}_{2}$ characteristic peak at $38.1^{\circ}$, these peaks were relatively weak in the XRD pattern. Finally, according to the XRD and TEM analyses above, the results revealed that $\mathrm{Ag}$ nanoparticles were formed and successfully loaded on the $\mathrm{TiO}_{2}$ surface.
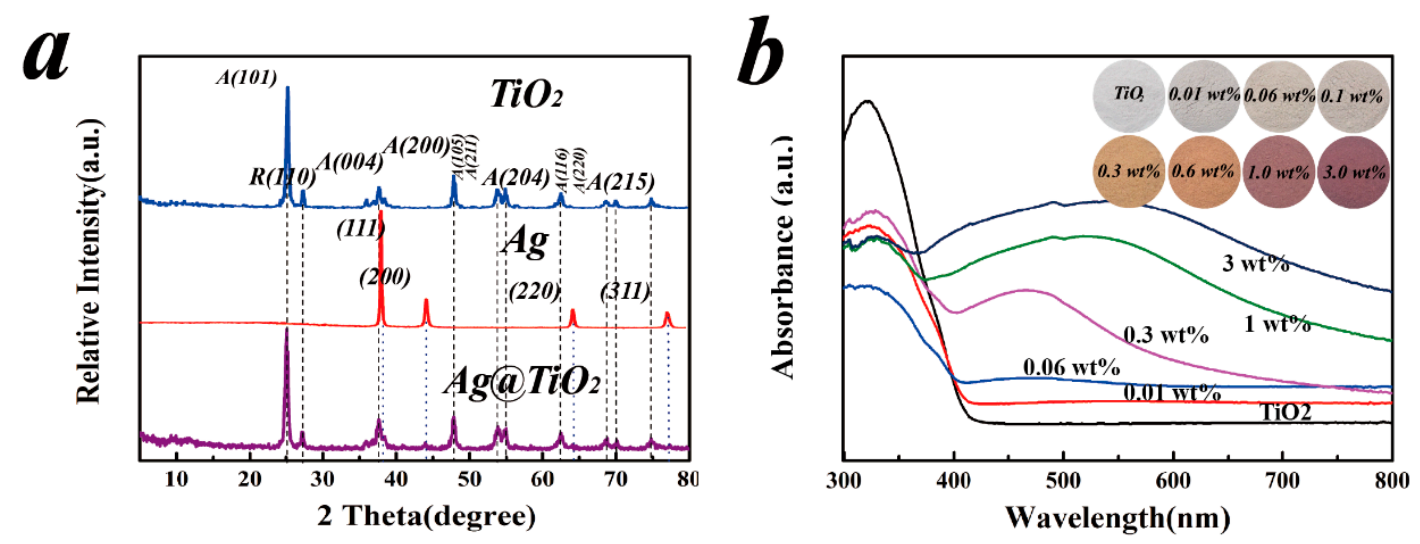

Figure 3. (a) XRD patterns of the $\mathrm{Ag} @ \mathrm{TiO}_{2}$ photocatalysts, in which $\mathrm{A}$ is anatase phase and $\mathrm{R}$ is rutile phase (no obvious Ag characteristic peak was found due to the ultra-trace loaded amount); (b) UV-vis diffuse spectra of $\mathrm{Ag} @ \mathrm{TiO}_{2}$ in different doping ratio (dried sample images with different $\mathrm{Ag}$ loadings, insert).

It was noteworthy that the obvious improvement of visible light absorption in the range of 400-700 nm could be noticed under the addition of Ag, which fits the gradual color change from ecru to purple (Figure 3b, insert). A significant optical adsorption enhancement could be observed in different Ag contents of $0.3 \mathrm{wt} \%, 1.0 \mathrm{wt} \%$ and $3.0 \mathrm{wt} \%$, whose absorption peaks appeared as a red shift moved from $480 \mathrm{~nm}$ to $580 \mathrm{~nm}$. However, there were almost no differences between Ag@ $\mathrm{TiO}_{2}$ doping ratios of $0.01 \mathrm{wt} \%$ and $0.06 \mathrm{wt} \%$, which were similar to bare $\mathrm{TiO}_{2}$. The observed peaks should be attributed to the surface plasmon resonance (SPR) effect of spatially confined electrons in $\mathrm{Ag}$ nanoparticles and this red-shift might be related to the interaction between $\mathrm{Ag}$ and $\mathrm{TiO}_{2}$. Moreover, the adsorption peak range might be continuously broadened as the Ag dosage increases.

\subsection{Catalytic Activity for $\mathrm{Cr}(V I)$ Photoreduction}

The catalytic properties of $\mathrm{Ag} @ \mathrm{TiO}_{2}$ photocatalysts were evaluated by $\mathrm{Cr}(\mathrm{VI})$ imitated heavy metal wastewater. As shown in Figure $4 \mathrm{a}, \mathrm{Cr}(\mathrm{VI})$ was firstly adsorbed onto the surface of $\mathrm{Ag} @ \mathrm{TiO}_{2}$ and adsorption equilibrium could be reached within $30 \mathrm{~min}$ under dark conditions. The aquatic $\mathrm{Cr}(\mathrm{VI})$ could be fully reduced to $\mathrm{Cr}$ (III) within 60 min under UV irradiation. The results illustrated that the $\mathrm{Cr}(\mathrm{VI})$ photocatalytic reduction efficiency got improved through Ag loading, which might be due 
to the following reasons. The photoresponse range could be enhanced, as presented in Figure $3 \mathrm{~b}$. Then, the Schottky junction would be formed at the interface with Ag deposition. Under light irradiation, photo-generated electrons $\left(e^{-}\right)$tend to migrate and accumulate on Ag nanoparticles which served as effective electron acceptors, and the extra acceptors subsequently promoted the $e^{-} / h^{+}$ separation efficiency and ultimately enhanced the photocatalytic reduction of $\mathrm{Cr}(\mathrm{VI})$. It is noteworthy that the amount of metal deposition has a great influence on the photocatalytic ability of the obtained photocatalysts. However, the photocatalytic efficiency gradually decreases once the Ag loading exceeds $0.06 \mathrm{wt} \%$, which is mainly due to the shielding effect by the excessive Ag coverage. In addition, when the Ag doping ratio gets higher $(>0.06 \mathrm{wt} \%)$, the extra $\mathrm{Ag}$ sites tend to act as the $e^{-} / h^{+}$recombination centers which may lead to the recombination enhancement and result in photon quantum efficiency drop. The effect of different concentration of Ethanol on $\mathrm{Cr}(\mathrm{VI})$ reduction is shown in Figure S3. Figure $4 \mathrm{~b}$ shows that the maximum UV-visible absorption of $\mathrm{Cr}(\mathrm{VI})$ solution was at $545 \mathrm{~nm}$, which was close to the standard value of $540 \mathrm{~nm}$. It can be obviously noticed that the $\mathrm{Cr}(\mathrm{VI})$ absorbance decreased rapidly in the first $20 \mathrm{~min}$, but slowly later on.
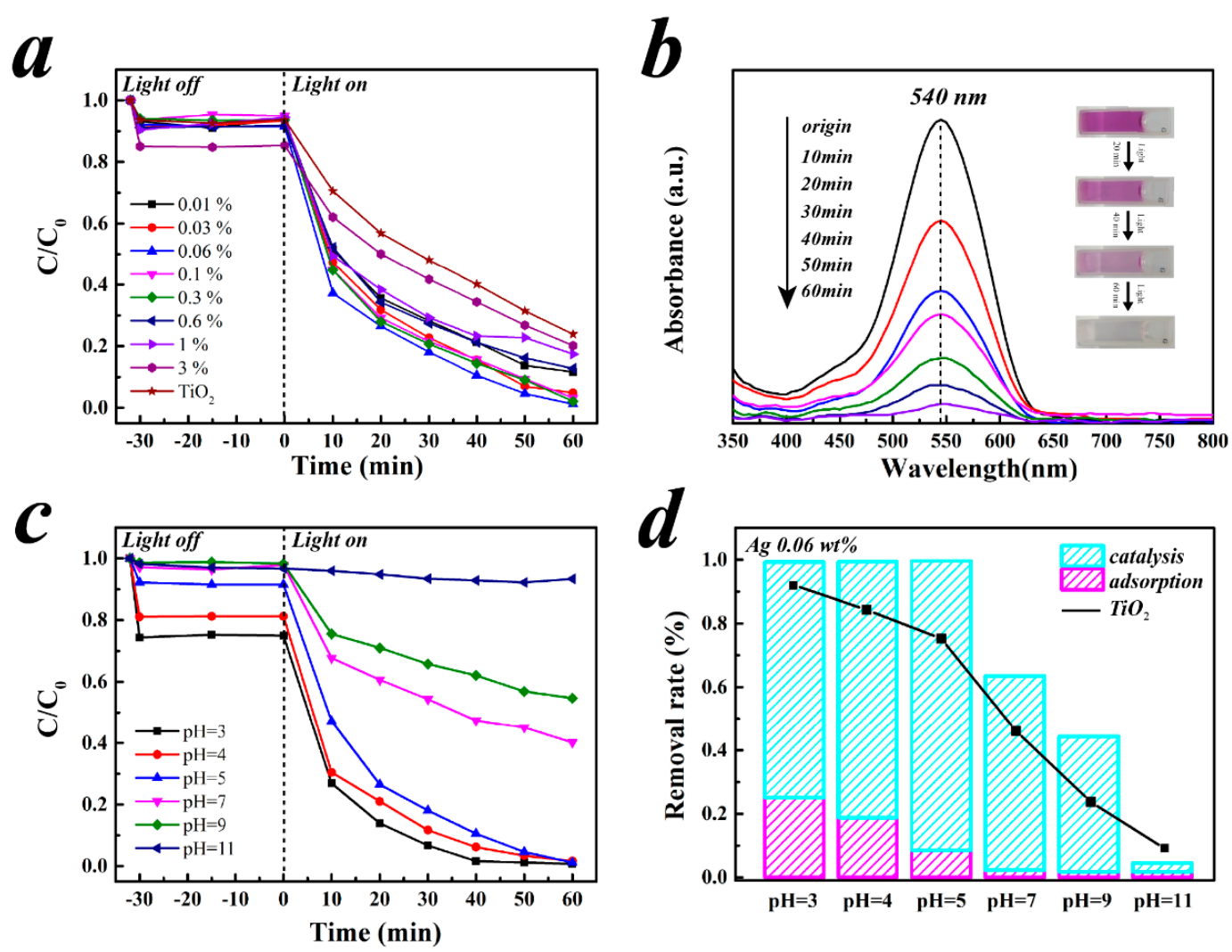

Figure 4. (a) Photocatalytic reduction efficiency by pure $\mathrm{TiO}_{2}$ and $\mathrm{Ag} @ \mathrm{TiO}_{2}$ composites with various Ag loading ratio (effect of different loading on adsorption balance before irradiation, insert); (b) UV-vis full wave band scanning of $\mathrm{Cr}(\mathrm{VI})$ under different irradiation times (the color change of $\mathrm{Cr}(\mathrm{VI})$ simples with different reduction time, insert); (c) Effect of different initial $\mathrm{pH}$ on $\mathrm{Cr}(\mathrm{VI})$ reduction rate; (d) The contribution of adsorption and photoreduction in $\mathrm{Cr}(\mathrm{VI})$ removal with different initial $\mathrm{pH}$ value using bare $\mathrm{TiO}_{2}$ and $\mathrm{Ag} @ \mathrm{TiO}_{2}$. (Both (b,c,d) using the simple with 0.06 wt \% Ag addition. The experimental conditions were $[\mathrm{Cat}]=1 \mathrm{~g} / \mathrm{L},[\mathrm{Cr}(\mathrm{VI})]_{0}=10 \mathrm{mg} / \mathrm{L}, 300 \mathrm{~W}$ and $60 \mathrm{~min}$ irradiation.

The impact of the initial $\mathrm{pH}$ on the $\mathrm{Cr}(\mathrm{VI})$ reduction was investigated, and its degradation efficiency was gradually reduced with $\mathrm{pH}$ increasing from 3.0 to 11.0 (Figure $4 \mathrm{c}, \mathrm{d}$ ). Therefore, the initial $\mathrm{pH}$ plays a significant role in the whole $\mathrm{Cr}(\mathrm{VI})$ photocatalytic reduction processes, which not only affects the surface adsorption but also the chromium's redox potential [35]. On the other hand, as the 
main catalytic reaction occurred on the interface, the adsorption ability to substrates would be a crucial role in the migration and captures of photogenerated carriers, which would directly affect the surface reactivity in the following photocatalytic reaction processes [36]. First of all, the $\mathrm{Cr}(\mathrm{VI})$ adsorption procedure was the prerequisite step for photocatalytic reduction, and the influence of initial $\mathrm{pH}$ on adsorption as well as resultant removal rate are shown in Figure $4 \mathrm{~d}$. $\mathrm{Cr}(\mathrm{VI})$ interface adsorption rapidly increases with $\mathrm{pH}$ decreasing. The maximum adsorption rate of $25 \%(\mathrm{pH}=3)$ was five times that of the lowest one $1 \%(\mathrm{pH}=11)$. This phenomenon was mainly due to the electrostatic attraction that the negatively charged $\mathrm{Cr}_{2} \mathrm{O}_{7}{ }^{2-}$ would spontaneously attach to positively charged subjects. According to the $\zeta$ potential testing in (Figure $\mathrm{S} 4$ ), the $\mathrm{pH}_{\mathrm{pzc}}\left(\mathrm{pH}\right.$ of zero-point charge) value of $\mathrm{Ag} @ \mathrm{TiO}_{2}$ was 5-6. So, when initial $\mathrm{pH}<5$, the surface would be positively charged which was in favor of the $\mathrm{Cr}_{2} \mathrm{O}_{7}{ }^{2-}$ adsorption. On the contrary, its surface would become negatively charged when $\mathrm{pH}>5$, which will result in a decrease in the adsorption capacity of $\mathrm{Cr}(\mathrm{VI})$. Therefore, it could be concluded that the adsorption capacity for $\mathrm{Cr}(\mathrm{VI})$ plays an important role in the photoreduction processes.

On the other hand, the metal pair's redox potential was either a significant factor that determines the photocatalytic ability of the resultant composites. As shown in Figure $4 \mathrm{c}$, the $\mathrm{Cr}(\mathrm{VI})$ photoreduction rate gradually drops with $\mathrm{pH}$ increasing. Specifically, the equilibrium could be reached within $40 \mathrm{~min}$ under the condition of $\mathrm{pH}=3$, but no obvious reduction could be found at $\mathrm{pH}=11$, which indicated that the oxidation ability of $\mathrm{Cr}(\mathrm{VI})$ was strongly affected by the $\mathrm{H}^{+}$concentration. Moreover, as the initial $\mathrm{pH}$ got higher, the redox potential of $\mathrm{Cr}(\mathrm{VI})$ decreased which leads to the drop of its oxidation ability (See Supplementary Materials, Equations (S1)-(S3)). It could be concluded that the photoreduction of $\mathrm{Cr}(\mathrm{VI})$ should be easier under acidic conditions and relatively difficult under neutral or alkaline conditions could be drawn. And, it also indicated that the negative effect of the proton deficiency could be inhibited via providing enough protons to the reaction system. Moreover, it is noteworthy that $\mathrm{Ag} @ \mathrm{TiO}_{2}$ exhibits a higher photocatalytic activity than pure $\mathrm{TiO}_{2}$ at the same $\mathrm{pH}$ (Figure $4 \mathrm{~d}$, line), which may be due to the available free electrons on the $\mathrm{Ag} @ \mathrm{TiO}_{2}$ surface or the active sites that can donate electrons to $\mathrm{Cr}(\mathrm{VI})$ being more than pure $\mathrm{TiO}_{2}$. Therefore, the initial $\mathrm{pH}$ impact on $\mathrm{Cr}(\mathrm{VI})$ reduction came from the integrative actions of various changes in the physicochemical properties of all the substances involved. The high efficiency of the obtained ultra-trace Ag doped $\mathrm{TiO}_{2}$ photocatalyst under acidic, neutral and alkaline conditions suggests its promising potential for wastewaters purification and treatment.

The effect of the catalyst dosage on $\mathrm{Cr}(\mathrm{VI})$ reduction is shown in Figure $5 \mathrm{a}$, the $\mathrm{Cr}(\mathrm{VI})$ reduction efficiency exhibited a positive dependence on the $\mathrm{Ag} @ \mathrm{TiO}_{2}$ dosage. There was not any reduction that could be detected in the absence of catalyst addition and the $\mathrm{Cr}(\mathrm{VI})$ removal efficiency gradually increased with dosage increasing. When the dosage was increased to $2 \mathrm{~g} / \mathrm{L}, \mathrm{Cr}(\mathrm{VI})$ could be fully reduced to $\mathrm{Cr}(\mathrm{III})$ within $30 \mathrm{~min}$, and the removal rate could still reach above $75 \%$ at a lower dosage $(0.5 \mathrm{~g} / \mathrm{L})$. It was mainly due to that the increasing dosage providing more reaction sites for $\mathrm{Cr}(\mathrm{VI})$ adsorption and photoreduction, as well as to producing more photogenerated electrons. 

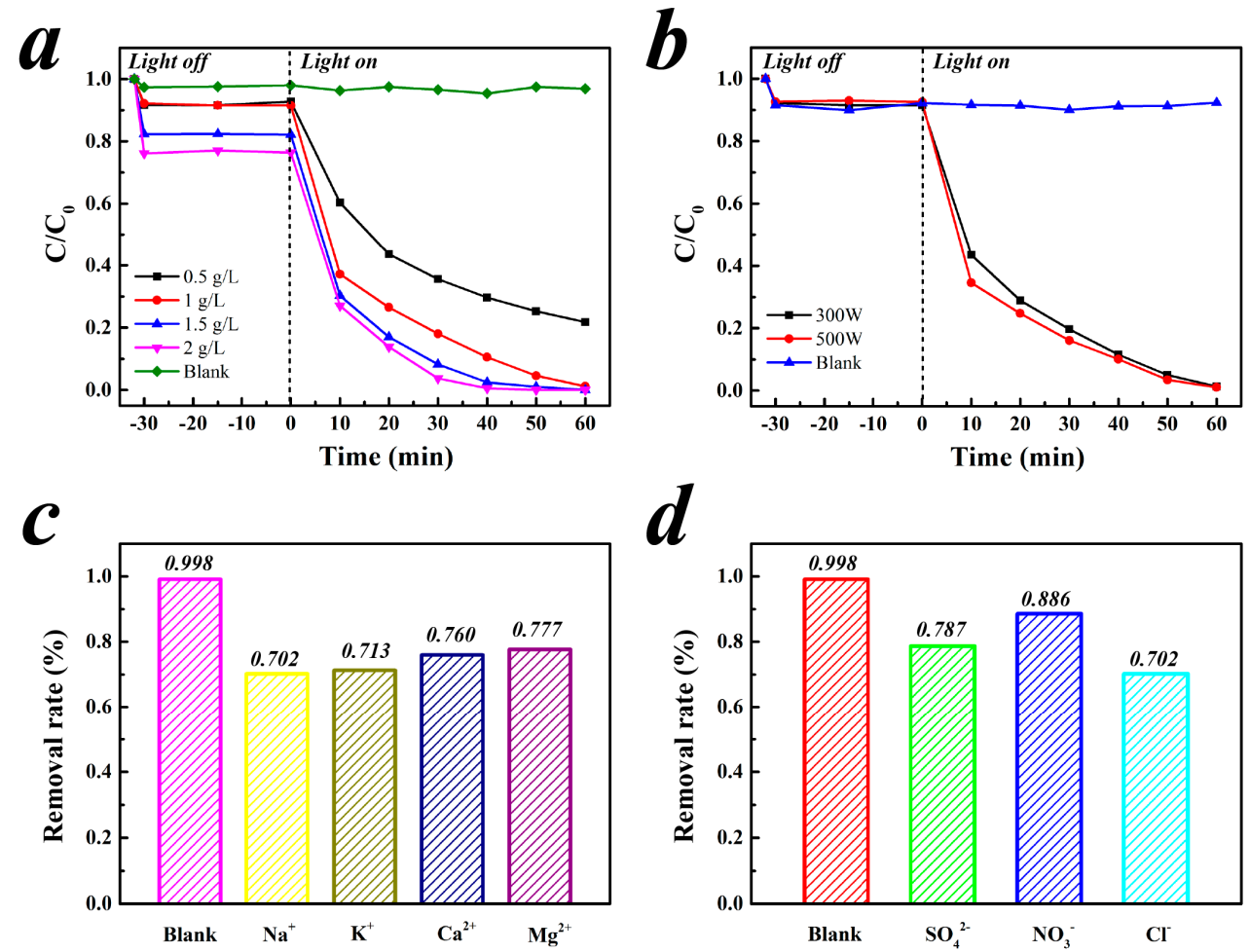

Figure 5. (a) Photocatalytic redaction of $\mathrm{Cr}(\mathrm{VI})$ by $\mathrm{Ag} @ \mathrm{TiO}_{2}$ composites of various dosages (the blank sample catalytic system showed that no obvious $\mathrm{Cr}(\mathrm{VI})$ degradation could be observed under UV irradiation); (b) Effect of illumination on $\mathrm{Cr}(\mathrm{VI})$ reduction; (c) Removal rate of co-existing cations on $\mathrm{Cr}(\mathrm{VI})$ reduction efficiency (metal salts:, $\mathrm{NaCl}, \mathrm{KCl}, \mathrm{MgCl}_{2}, \mathrm{CaCl}_{2}$; (d) Removal rate of co-existing anions on $\mathrm{Cr}(\mathrm{VI})$ reduction efficiency (metal salts: $\mathrm{NaCl}, \mathrm{Na}_{2} \mathrm{SO}_{4}, \mathrm{NaNO}_{3}$ ); Both (a-d) using the $\mathrm{Ag} @ \mathrm{TiO}_{2}$ with 0.06 wt \%. The experimental conditions were $[\mathrm{Cr}(\mathrm{VI})]_{0}=10 \mathrm{mg} / \mathrm{L}$, initial $\mathrm{pH}=5$.

Figure $5 \mathrm{~b}$ shows the $\mathrm{Cr}(\mathrm{VI})$ photocatalytic reduction under the UV-light intensity that varied from $0 \mathrm{~W}$ (blank) to $500 \mathrm{~W}$. The removal rate for adsorption was maintained obviously at less than $10 \%$ until the equilibrium and the photoreduction was significantly improved under UV-light compared to the blank one. However, it should be noted that there are little differences between the $300 \mathrm{~W}$ and $500 \mathrm{~W}$ mercury lamps although the intense illumination might facilitate electron production. The $\mathrm{Cr}(\mathrm{VI})$ removal efficiency could reach about $95 \%$ within 50 min under the illumination intensities $300 \mathrm{~W}$ or $500 \mathrm{~W}$. Therefore, it would be more advisable to utilize the $300 \mathrm{~W}$ lamp for considering the energy consuming.

Since industrial wastewater contains a variety of conventional materials which are usually comprised of routine anions and cations, these co-existing substances tend to reduce the catalytic performance of $\mathrm{Ag} @ \mathrm{TiO}_{2}$ composites. To explore the potential synergistic effect between co-existing ions and $\mathrm{Ag} @ \mathrm{TiO}_{2}$ composites, a series of co-existing ions, such as $\mathrm{Cl}^{-}, \mathrm{SO}_{4}{ }^{2-}, \mathrm{NO}_{3}{ }^{-}$and $\mathrm{Na}^{+}, \mathrm{K}^{+}$, $\mathrm{Mg}^{2+}, \mathrm{Ca}^{2+}$ ions were utilized in the control group. As the amount of co-existing ions in practical industrial wastewater usually reaches thousands of $\mathrm{ppm}$, in order to imitate the actual situation, its concentrations are all set at $0.1 \mathrm{~mol} / \mathrm{L}$, which in turn may affect the rate of photocatalytic reduction.

As illustrated in Figure 5c, all co-existing ions have a significant impact on the $\mathrm{Cr}(\mathrm{VI})$ reduction process. Two sequences on the impact of co-existing ions were drawn through experiments, like $\mathrm{Cl}^{-}>\mathrm{SO}_{4}{ }^{2-}>\mathrm{NO}_{3}{ }^{-}$and $\mathrm{Na}^{+}>\mathrm{K}^{+}>\mathrm{Ca}^{2+}>\mathrm{Mg}^{2+}$. The main reason for the inhibiting effect by co-existing anions was the competition between anionic and dichromate adsorption and active sites on the surface. To be more specific, $\mathrm{NO}_{3}{ }^{-}$have very few effects whereas $\mathrm{SO}_{4}{ }^{2-}$ or $\mathrm{Cl}^{-}$were more rapidly adsorbed by the catalyst than $\mathrm{Cr}(\mathrm{VI})$, which is similar to a previous report [37]. Obviously, the $\mathrm{Na}^{+}$ introduced together has a certain influence on the removal rate of the experiment (Figure $5 d$ ). As for 
cations, the impacts on photoreduction can be neglected since $\mathrm{Na}^{+}, \mathrm{K}^{+}, \mathrm{Mg}^{2+}$ and $\mathrm{Ca}^{2+}$ ions are already in their highest oxidation states, so they can neither capture radicals or photo-generated holes [38]. Therefore, the inhibiting phenomenon by cations may be caused by the presence of $\mathrm{Cl}^{-}$. The $\mathrm{Cr}(\mathrm{VI})$ removal rates in $\mathrm{Mg}^{2+}$ and $\mathrm{Ca}^{2+}$-containing systems are better than that in $\mathrm{K}^{+}$and $\mathrm{Na}^{+}$-containing systems, which may be due to the higher affinity of higher valence cations for $\mathrm{Cr}_{2} \mathrm{O}_{7}{ }^{2-}$, and enhances anion transfer rate in solution. For the same valence state, the larger the ion radius $\left(\mathrm{K}^{+}>\mathrm{Na}^{+}\right.$or $\mathrm{Ca}^{2+}$ $\left.>\mathrm{Mg}^{2+}\right)$, the ion center contains more positive charge which promotes the anions' adsorption [39].

Additionally, the reusability of the $\mathrm{Ag}_{\mathrm{O}} \mathrm{TiO}_{2}$ photocatalyst was also evaluated. The performance of $\mathrm{Ag} @ \mathrm{TiO}_{2}$ nanocomposite within five recycles is shown in Figure 6a. Obviously, the removal efficiency slowly decreases with the recycling continuing. It may be due to that the increasing amount of adsorbed $\mathrm{Cr}(\mathrm{III})$ on $\mathrm{Ag} @ \mathrm{TiO}_{2}$ which will inhibit its surface adsorption and active site reduction properties. To further identify the adsorbed species on the catalyst surface, high resolution XPS spectra of the dry Ag@ $\mathrm{TiO}_{2}$ sample after the reaction were used to characterize the changes in the catalyst surface. The XPS spectra of $\mathrm{Cr}$ peaks were obviously presented in Figure $6 \mathrm{~b}$. The bands at binding energy of $577.2 \mathrm{eV}$ and $585.9 \mathrm{eV}$ were attributed to $\mathrm{Cr}$ (III) $2 p_{3 / 2}$ and $\mathrm{Cr}$ (III) $2 p_{1 / 2}$, respectively. The peaks at $580.6 \mathrm{eV}$ belonged to the $\mathrm{Cr}(\mathrm{VI}) 2 p_{3 / 2}$. The results show that the adsorption and reduction were simultaneously carried out during the $\mathrm{Cr}(\mathrm{VI})$ photoreduction and the generated $\mathrm{Cr}(\mathrm{III})$ was also adsorbed on the $\mathrm{Ag} @ \mathrm{TiO}_{2}$ surface, which results in a low $\mathrm{Cr}(\mathrm{VI})$ reduction rate. Second, it was found that the XPS of $\mathrm{Ag}$ shifted to a certain extent after the reaction (Figure S5), indicating that more $\mathrm{Ag}_{2} \mathrm{O}$ was produced. It is possible that the ability to transfer electrons might decreased, which will lead to a decline in catalytic performance. However, after five consecutive cycles, $\mathrm{Ag} @ \mathrm{TiO}_{2}$ removal rate could still reach $62 \%$, indicating that the resultant photocatalyst has a relatively good reusability.

It is well known that the selective adsorption of $\mathrm{Cr}(\mathrm{VI})$ and the desorption of $\mathrm{Cr}(\mathrm{III})$ at the surface of photocatalysts are very important factors in determining the photocatalytic reduction. The modification of $\mathrm{Ti}^{3+}$ and hydroxyl groups can enhance the positive charge on the surface of the catalyst and further increase the preferential adsorption of $\mathrm{Cr}(\mathrm{VI})$ and repulsion of $\mathrm{Cr}(\mathrm{III})$ by electrostatic action [40]. Moreover, it might be a simpler way to make the catalyst aspects of active-site reusable by external force, like: thermal, chemical reactivation, calcine, and Ultrasonic cleaning et al.
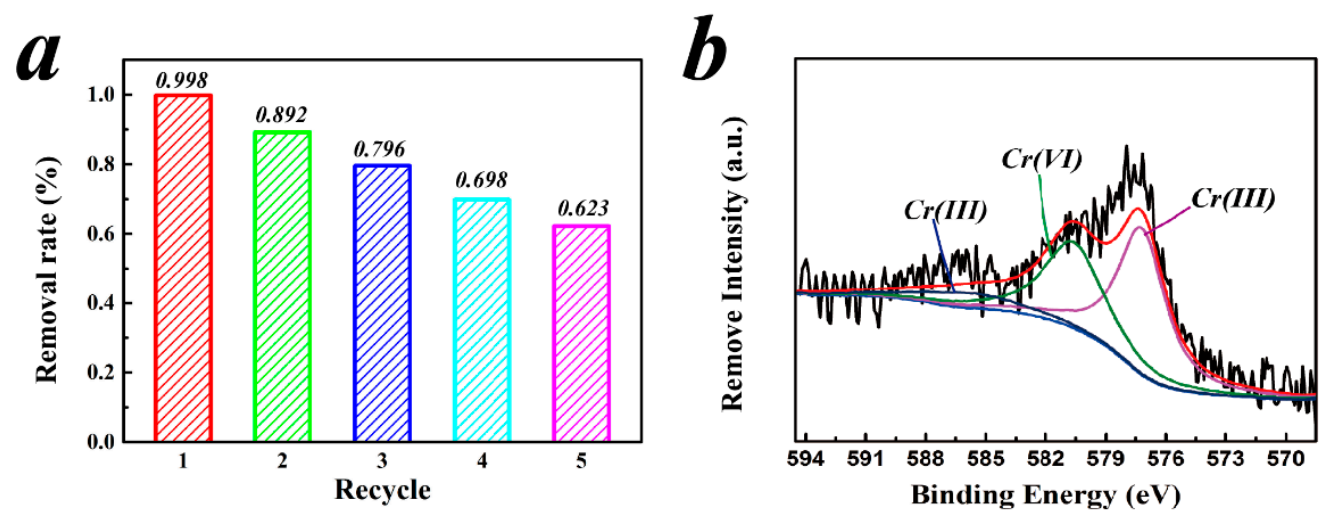

Figure 6. (a) The reusability of synthetic catalysts by 5 recycle on $\mathrm{Cr}(\mathrm{VI})$ removal (using the $\mathrm{Ag}_{\mathrm{TiO}}$ with 0.06 wt \%); (b) High resolution XPS of $\mathrm{Cr}$ on the surface of $\mathrm{Ag} @ \mathrm{TiO}_{2}$ catalyst. The experimental conditions were $\left.[\mathrm{Cr}(\mathrm{VI})]_{0}=10 \mathrm{mg} / \mathrm{L}\right)$.

\subsection{Kinetic Modeling Study}

The reaction between $\mathrm{Ag} @ \mathrm{TiO}_{2}$ photocatalysts and $\mathrm{Cr}(\mathrm{VI})$ was related to the multiphase surface reaction. Langumir-Hinshelwood first order kinetic model was applied to evaluate the reaction kinetics.

$$
\mathrm{r}_{0}=-\frac{\mathrm{dC}}{\mathrm{dt}}=\frac{\mathrm{kKCs}}{1+\mathrm{KCs}}
$$


where $\mathrm{r}_{0}$ is the initial photocatalytic reduction efficiency $(\mathrm{mg} / \mathrm{L} \cdot \mathrm{min})$; $\mathrm{t}$ is the reaction time $(\mathrm{min}) ; \mathrm{k}$ is the reaction efficiency constant $\left.\left(\mathrm{min}^{-1}\right)\right)$; $\mathrm{K}$ is the reaction equilibrium constant; and $\mathrm{C}_{\mathrm{s}}$ is the reactant concentration $(\mathrm{mg} / \mathrm{L}) ; \mathrm{k}$ and $\mathrm{K}$ are determined by many factors in the reaction system, including the amount of catalyst, light intensity, initial concentration of reactants, reaction temperature, physical properties of the reactants, gas phase oxygen concentration, etc.

When the reaction substrate concentration is rather low, $K C \ll 1$, the equation can be simplified to the apparent first order equation:

$$
\mathrm{r}_{0}=-\frac{\mathrm{dC}}{\mathrm{dt}}=\mathrm{kKC}=\mathrm{k}_{\mathrm{ap}} \mathrm{C}
$$

where $\mathrm{k}_{\mathrm{ap}}$ is the apparent rate constant of a pseudo first order reaction. In the beginning of the reaction, $t=0, C_{t}=C_{0}$, the equation can be obtained after deformation:

$$
\ln \left(\frac{C_{t}}{C_{0}}\right)=-k_{a p} t+b
$$

where $\mathrm{C}_{\mathrm{t}}$ is the concentration of $\mathrm{Cr}(\mathrm{VI})$ in the solution at $\mathrm{t} \min$; $\mathrm{C}_{0}$ is the initial $\mathrm{Cr}(\mathrm{VI})$ concentration; $\mathrm{b}$ represents a constant; $\mathrm{k}_{\mathrm{ap}}$ is the apparent rate constant $\left(\mathrm{min}^{-1}\right)$.

From Figure 7 , it can be seen that $\ln \left(C_{t} / C_{0}\right)-t$ is in a good linear relationship and its performance fits the first order reaction. The apparent reaction kinetic constant can be applied to estimate the total reaction rate, and then compare the photocatalytic efficiency under different conditions. In Figure 7 , initial $\mathrm{pH}$ and $\mathrm{Ag}$ loading affected the obtained reaction kinetic constant. The first-order kinetic equation, reaction rate constant, reaction rate and the correlation coefficients $\left(R^{2}\right)$ of the photocatalytic reaction under different conditions are shown in Table 2. It can be seen that the apparent rate constant $\mathrm{k}_{\mathrm{ap}}$ decreases as initial $\mathrm{pH}$ grows, and $\mathrm{k}_{\mathrm{ap}}$ under acidic condition $(\mathrm{pH}=3)$ was about six times as much as the neutral one $(\mathrm{pH}=7)$ and quickly dropped to about zero under alkaline conditions $(\mathrm{pH}=11)$, indicating that acidic environment promotes the photocatalytic reduction processes. In addition, $\mathrm{k}_{\mathrm{ap}}$ presents a trend that gradually rises to $0.0534 \mathrm{~min}^{-1}$ until the silver doping ratio reaches $0.06 \mathrm{wt} \%$ and then continuously decreases to $0.0211 \mathrm{~min}^{-1}$ as the $\mathrm{Ag}$ loading grows to $3.0 \mathrm{wt} \%$. Furthermore, the results show that $\mathrm{Cr}(\mathrm{VI})$ reduction efficiency by $0.06 \mathrm{wt} \% \mathrm{Ag}$ loading was 2.5 times compared to pure $\mathrm{TiO}_{2}$, indicating that suitable $\mathrm{Ag}$ loading on $\mathrm{TiO}_{2}$ surface promoted its photocatalytic ability significantly.
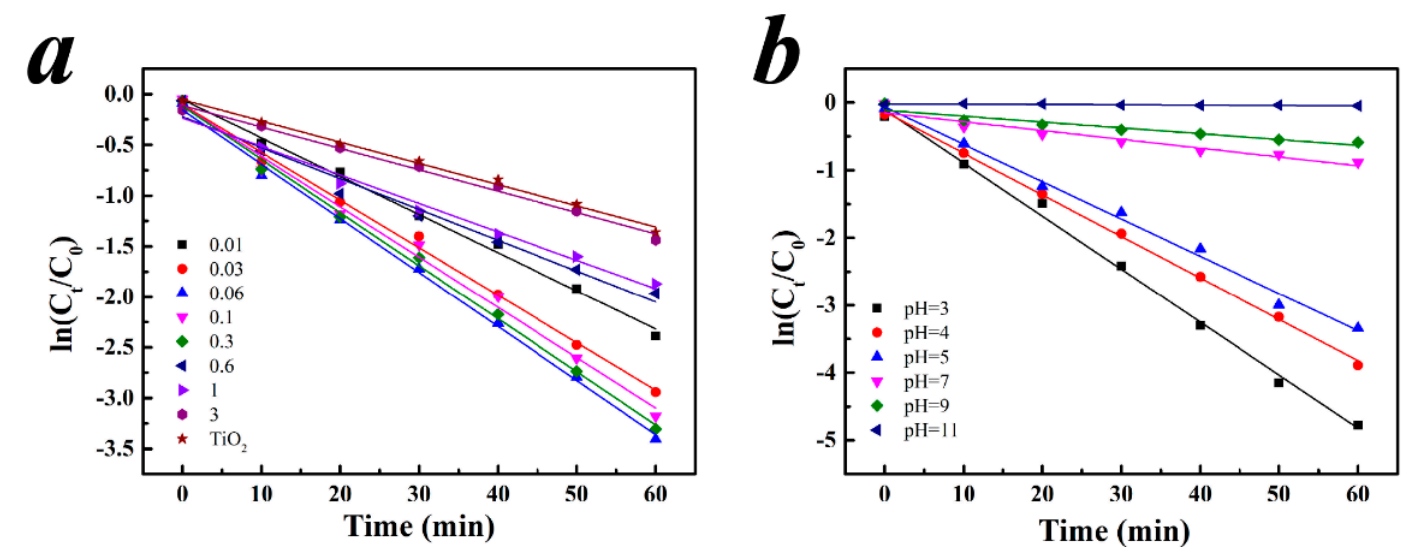

Figure 7. The study of kinetics at different Ag loadings (a) and $\mathrm{pH}$ values (b). 
Table 2. The relevant parameters obtained from kinetic study.

\begin{tabular}{|c|c|c|c|c|}
\hline & Kinetics Equation & $k_{\text {ap }}\left(\min ^{-1}\right)$ & $r_{0}(\mathrm{mg} / \mathrm{L} \cdot \min )$ & $R^{2}$ \\
\hline $0.01 \mathrm{wt} \%$ & $\ln \left(C_{t} / C_{0}\right)=0.0377 t-0.0549$ & 0.0377 & 0.3770 & 0.9947 \\
\hline $0.03 \mathrm{wt} \%$ & $\ln \left(C_{t} / C_{0}\right)=0.0470 t-0.1046$ & 0.0470 & 0.4700 & 0.9954 \\
\hline $0.06 \mathrm{wt} \%$ & $\ln \left(C_{t} / C_{0}\right)=0.0534 t-0.1572$ & 0.0534 & 0.5340 & 0.9966 \\
\hline $0.1 \mathrm{wt} \%$ & $\ln \left(C_{t} / C_{0}\right)=0.0497 t-0.1149$ & 0.0497 & 0.4970 & 0.9895 \\
\hline 0.3 wt $\%$ & $\ln \left(C_{t} / C_{0}\right)=0.0525 t-0.1183$ & 0.0525 & 0.5250 & 0.9963 \\
\hline 0.6 wt $\%$ & $\ln \left(C_{t} / C_{0}\right)=0.0304 t-0.2233$ & 0.0304 & 0.3040 & 0.9731 \\
\hline 1 wt $\%$ & $\ln \left(C_{t} / C_{0}\right)=0.0281 t-0.2356$ & 0.0281 & 0.2810 & 0.9858 \\
\hline $3 w t \%$ & $\ln \left(C_{t} / C_{0}\right)=0.0211 t-0.1137$ & 0.0211 & 0.2110 & 0.9909 \\
\hline Bare & $\ln \left(C_{t} / C_{0}\right)=0.0209 t-0.0562$ & 0.0209 & 0.2090 & 0.9937 \\
\hline $\mathrm{pH}=3$ & $\ln \left(C_{t} / C_{0}\right)=0.0786 t-0.1070$ & 0.0786 & 0.7860 & 0.9954 \\
\hline $\mathrm{pH}=4$ & $\ln \left(C_{t} / C_{0}\right)=0.615 t-0.1347$ & 0.0615 & 0.6150 & 0.9989 \\
\hline $\mathrm{pH}=5$ & $\ln \left(C_{t} / C_{0}\right)=0.0552 t-0.0652$ & 0.0552 & 0.5520 & 0.9920 \\
\hline $\mathrm{pH}=7$ & $\ln \left(C_{t} / C_{0}\right)=0.0131 t-0.1523$ & 0.0131 & 0.1310 & 0.9213 \\
\hline $\mathrm{pH}=9$ & $\ln \left(C_{t} / C_{0}\right)=0.0086 t-0.1151$ & 0.0086 & 0.0860 & 0.9039 \\
\hline $\mathrm{pH}=11$ & $\ln \left(C_{t} / C_{0}\right)=-0.0222$ & 0.0001 & 0.0010 & 0.5126 \\
\hline $\mathrm{Na}^{+}$ & $\ln \left(C_{t} / C_{0}\right)=0.0189 t-0.0560$ & 0.0189 & 0.1890 & 0.9948 \\
\hline $\mathrm{K}^{+}$ & $\ln \left(C_{t} / C_{0}\right)=0.0175 t-0.0836$ & 0.0175 & 0.1750 & 0.9881 \\
\hline $\mathrm{Ca}^{2+}$ & $\ln \left(C_{t} / C_{0}\right)=0.0202 t-0.0607$ & 0.0202 & 0.2020 & 0.9915 \\
\hline $\mathrm{Mg}^{2+}$ & $\ln \left(C_{t} / C_{0}\right)=0.0209 t-0.0890$ & 0.0209 & 0.2090 & 0.9895 \\
\hline $\mathrm{SO}_{4}^{2-}$ & $\ln \left(C_{t} / C_{0}\right)=0.0234 t-0.1560$ & 0.0234 & 0.2340 & 0.9808 \\
\hline $\mathrm{NO}_{3}^{-}$ & $\ln \left(C_{t} / C_{0}\right)=0.0320 t-0.1758$ & 0.0320 & 0.3202 & 0.9843 \\
\hline $\mathrm{Cl}^{-}$ & $\ln \left(C_{t} / C_{0}\right)=0.0190 t-0.0600$ & 0.0190 & 0.1900 & 0.9948 \\
\hline
\end{tabular}

\subsection{Mechanism of Photoreduction}

To identify the radical species involved in the reduction of $\mathrm{Cr}(\mathrm{VI})$ by $\mathrm{Ag} @ \mathrm{TiO}_{2}$ system, EPR experiments using DMPO as the spin-trapping agent were carried out. EPR analysis results of TiO and $\mathrm{Ag} @ \mathrm{TiO}_{2}$ solids are shown in Figure 8a; it can be clearly seen that one signal appeared after UV irradiation both for bare $\mathrm{TiO}_{2}$ and $\mathrm{Ag} @ \mathrm{TiO}_{2}$; the g-factors were 2.0024 and 2.0019, respectively, which was considered to be a free electron in the conduction band of $\mathrm{TiO}_{2}$ or an oxyanion vacancy. The enhancement of the peak signal intensity proves that more free electrons and oxygen vacancies are generated in the $\mathrm{Ag} @ \mathrm{TiO}_{2}$ system, which may be due to the photogenerated electrons being transferred to silver elements and stored therein.

Figure $8 \mathrm{c}, \mathrm{d}$ shows the EPR spectra of DMPO-trapped $\mathrm{O}_{2}{ }^{\bullet-}$ in methanol medium and DMPO-trapped ${ }^{\bullet} \mathrm{OH}$ in aqueous medium which have been investigated in the active radical species for the $\mathrm{TiO}_{2}$ and $\mathrm{Ag} @ \mathrm{TiO}_{2}$. It be able to evidently noted that four characteristic peaks (1:2:2:1) of DMPO- ${ }^{\bullet} \mathrm{OH}$ adducts and six characteristic peaks of the $\mathrm{DMPO}^{-} \mathrm{O}_{2}^{\bullet-}$ adducts were observed on $\mathrm{TiO}_{2}$ or $\mathrm{Ag} @ \mathrm{TiO}_{2}$ nanocomposite systems under UV light irradiation, but no signal was detected in the dark. It could be noted that, the intensity signals of the hydroxyl radical and superoxide radical species formed in $\mathrm{Ag} @ \mathrm{TiO}_{2}$ were stronger than those in $\mathrm{TiO}_{2}$ under UV irradiation, which represent the sample of $\mathrm{Ag} @ \mathrm{TiO}_{2}$ effectively promoted electron/hole pair separation and prolonged the lifetime. This, in turn, explains why there is a higher photocatalytic activity of $\mathrm{Ag} @ \mathrm{TiO}_{2}$ than $\mathrm{TiO}_{2}$ toward the contaminants removal. 


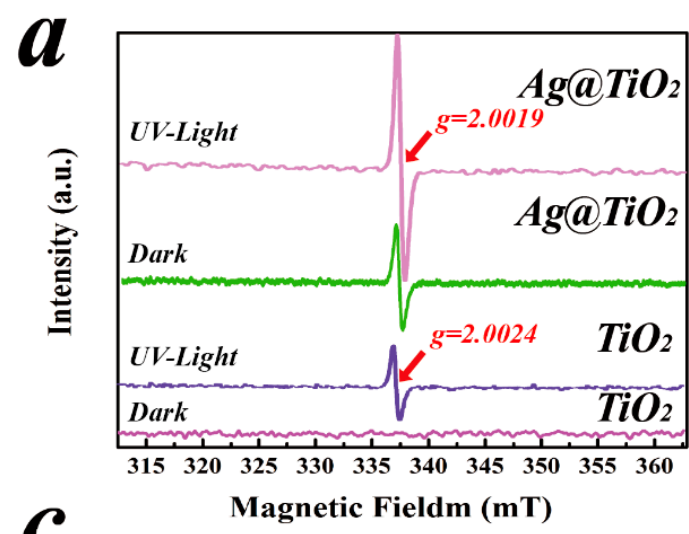

c

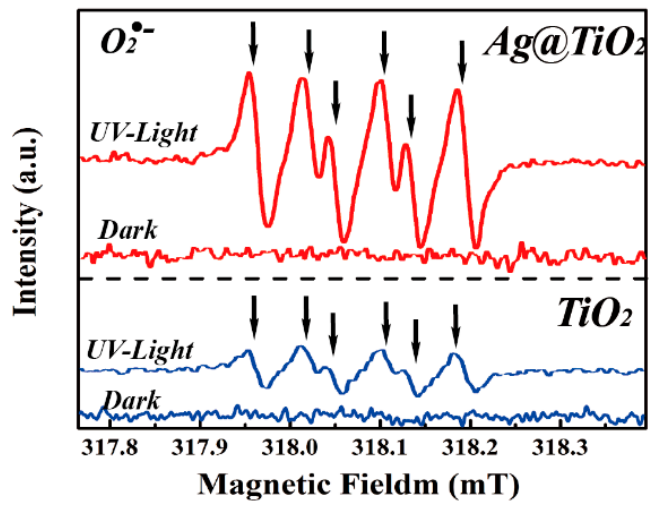

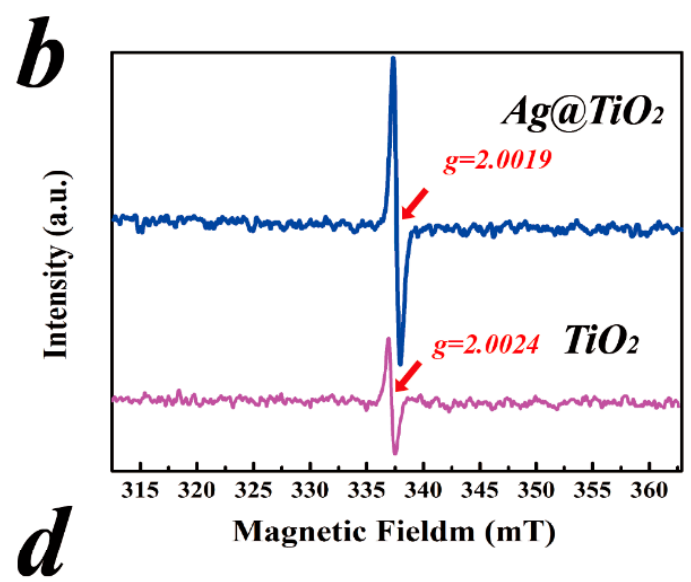

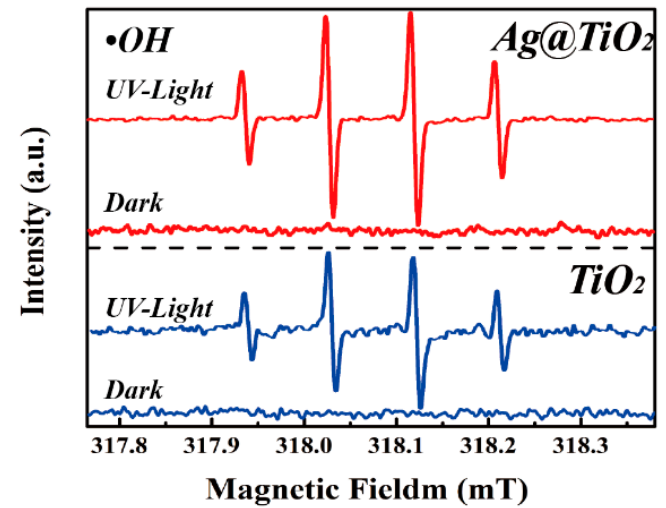

Figure 8. (a) EPR spectra in activation of the as prepared $\mathrm{Ag} @ \mathrm{TiO}_{2}(0.06 \mathrm{wt} \%)$ and pure $\mathrm{TiO}_{2}$ powder; (b) EPR difference spectrum between dark and UV-light of $\mathrm{TiO}_{2}$ and $\mathrm{Ag} @ \mathrm{TiO}_{2}$; (c) EPR spectra of

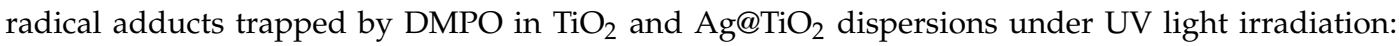
DMPO- $\mathrm{O}_{2}{ }^{\bullet-}$ formed in irradiated methanol dispersions; (d) DMPO- ${ }^{\bullet} \mathrm{OH}$ formed in irradiated aqueous dispersions. Reaction conditions: $\left[\mathrm{Ag} @ \mathrm{TiO}_{2}\right]=1 \mathrm{mg} / \mathrm{mL},\left[\mathrm{TiO}_{2}\right]=1 \mathrm{mg} / \mathrm{mL},[\mathrm{DMPO}]=100 \mathrm{mM}$, [Illumination time] $=5 \mathrm{~min}$.

To further identify the elemental constitution and its valences, the resultant $\mathrm{Ag} @ \mathrm{TiO}_{2}$ photocatalyst was characterized via XPS spectra. The full spectrum of $\mathrm{TiO}_{2}$ loaded with $\mathrm{Ag}$ nanoparticles was illustrated in Figure 9a and Figure S6, the main elements were Ti, O, C and Ag. The $\mathrm{C}$ emergence is due to the introduction of exogenous substances during the testing processes. As presented in Figure 9b, it can be seen that the loading of silver nanoparticles has obvious effects on the binding of Ti $2 p$ orbitals. Compared with pure $\mathrm{TiO}_{2}$, the combination of $\mathrm{Ti}_{2} p_{1 / 2}$ and $\mathrm{Ti} 2 p_{3 / 2}$ can change from to $465.13 \mathrm{eV}$ and $459.45 \mathrm{eV}$ to $458.77 \mathrm{eV}$ and $464.57 \mathrm{eV}$, respectively. The affection was due to that the load of $\mathrm{Ag}$ makes the heterojunction between $\mathrm{Ag}$ and $\mathrm{TiO}_{2}$, and the plasmonic effect produced by Ag makes the electron field which would influence $\mathrm{TiO}_{2}$. Figure $9 \mathrm{c}$ shows the XPS peak of $\mathrm{O} 1 \mathrm{~s}$, from which we can find the asymmetry peak of $\mathrm{O}$. Therefore, two peaks were obtained by Gauss Lorentz method. The peaks at $531.87 \mathrm{eV}$ and $530.79 \mathrm{eV}$ were assigned to Ti-OH bond and the Ti-O-Ti bond in lattice oxygen, respectively. The binding energy at $533.57 \mathrm{eV}$ was due to the adsorbed oxygen on the catalyst surface. The X-ray spectrum of $\mathrm{Ag} 3 d$ is shown in Figure $9 \mathrm{~d}$, indicating that the XPS peak of $\mathrm{Ag} 3 d$ mainly contains two characteristic peaks. The binging energies of $\mathrm{Ag} 3 d_{3 / 2}$ and $\mathrm{Ag} 3 d_{5 / 2}$ were observed at $368.2 \mathrm{eV}$ and $374.2 \mathrm{eV}$, respectively. The results showed that the difference of binding energies between $\mathrm{Ag} 3 d_{5 / 2}$ and $\mathrm{Ag} 3 d_{3 / 2}$ was $6.1 \mathrm{eV}$, revealing that the Ag element depositing on $\mathrm{TiO}_{2}$ surface exists in the form of zero valences, which was reported in the previous literature $[27,41]$. To further elucidate the surface metal composition, $\mathrm{Ag} 3 d$ peaks of the catalysts were deconvoluted, 
and the content of Ag was calculated to be $0.6655 \%$ (Table S3). Combined with the XRD and HRTEM results, the existence of $\mathrm{Ag}$ and $\mathrm{TiO}_{2}$ nanoparticles in the resultant compound can be further proved.
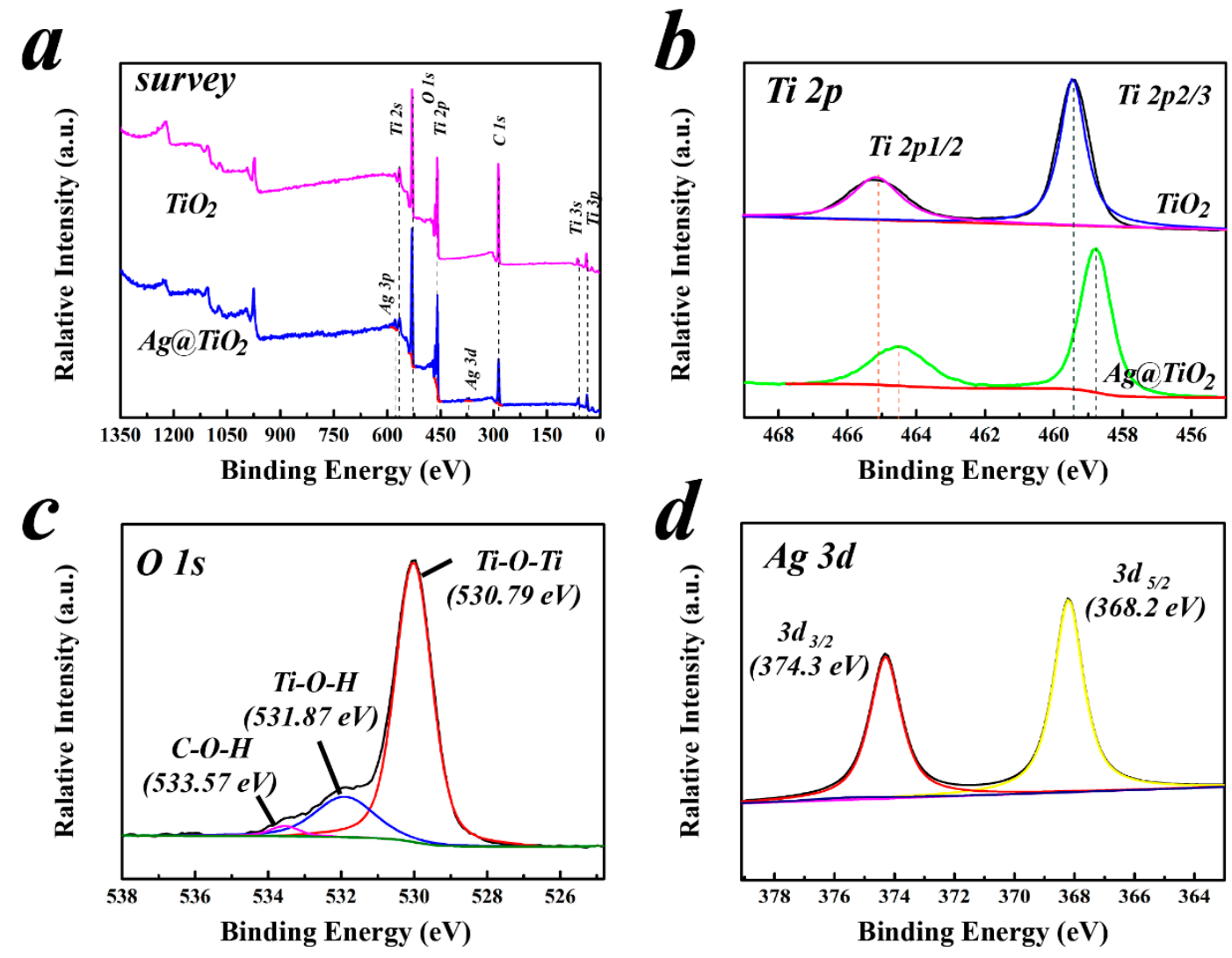

Figure 9. The survey spectrum (a); Ti 2p (b), O 1s (c), and Ag 3d (d) XPS spectra of the Ag@ $\mathrm{TiO}_{2}$ composites (0.6 wt \%, $30 \mathrm{~min}$ irradiation).

The photocatalytic reaction was considered to be a heterogeneous interfacial reaction, and mainly contained two parts of the reaction mechanism (Figure 10). Firstly, the good adsorption of $\mathrm{Cr}(\mathrm{VI})$ on the surface of $\mathrm{Ag} @ \mathrm{TiO}_{2}$ was a prerequisite of photoreduction. Then, the $\mathrm{Cr}(\mathrm{VI})$ was reduced to $\mathrm{Cr}(\mathrm{III})$ by using photogenerated electrons from the light source. Adsorption of oxygen on the catalyst surface as an electron competitor was generally considered to have the potential to reduce the rate in the photoreduction reaction. Oxygen reduction state $\left(\mathrm{O}_{2}{ }^{\bullet-}\right)$ can promote the photoreduction of $\mathrm{Cr}(\mathrm{VI})$ in $\mathrm{TiO}_{2}$ system as electron transfer intermediates [42]. From the results of photoreduction experiments and the EPR spectra of DMPO-trapped $\mathrm{O}_{2}{ }^{\bullet-}$, it can be seen that a substantial increase of $\mathrm{O}_{2}{ }^{\bullet-}$ did not inhibit the reduction activity of photocatalysis, which may indicate the $\mathrm{O}_{2}{ }^{\bullet-}$ as a reduced product formed by obtaining electrons and also has strong reducibility, resulting in the transformation of $\mathrm{Cr}(\mathrm{VI})$, a strongly oxidizing species, to $\mathrm{Cr}(\mathrm{III})$. Therefore, the photoreduction of $\mathrm{Cr}(\mathrm{VI})$ by $\mathrm{Ag} @ \mathrm{TiO}_{2}$ system under UV light is a complex synergistic processes with multi-actions. However, more photogenerated electrons were probably exposed, and resulted in a higher photocatalytic activity due to the loading of $\mathrm{Ag}$ on $\mathrm{TiO}_{2}$. 

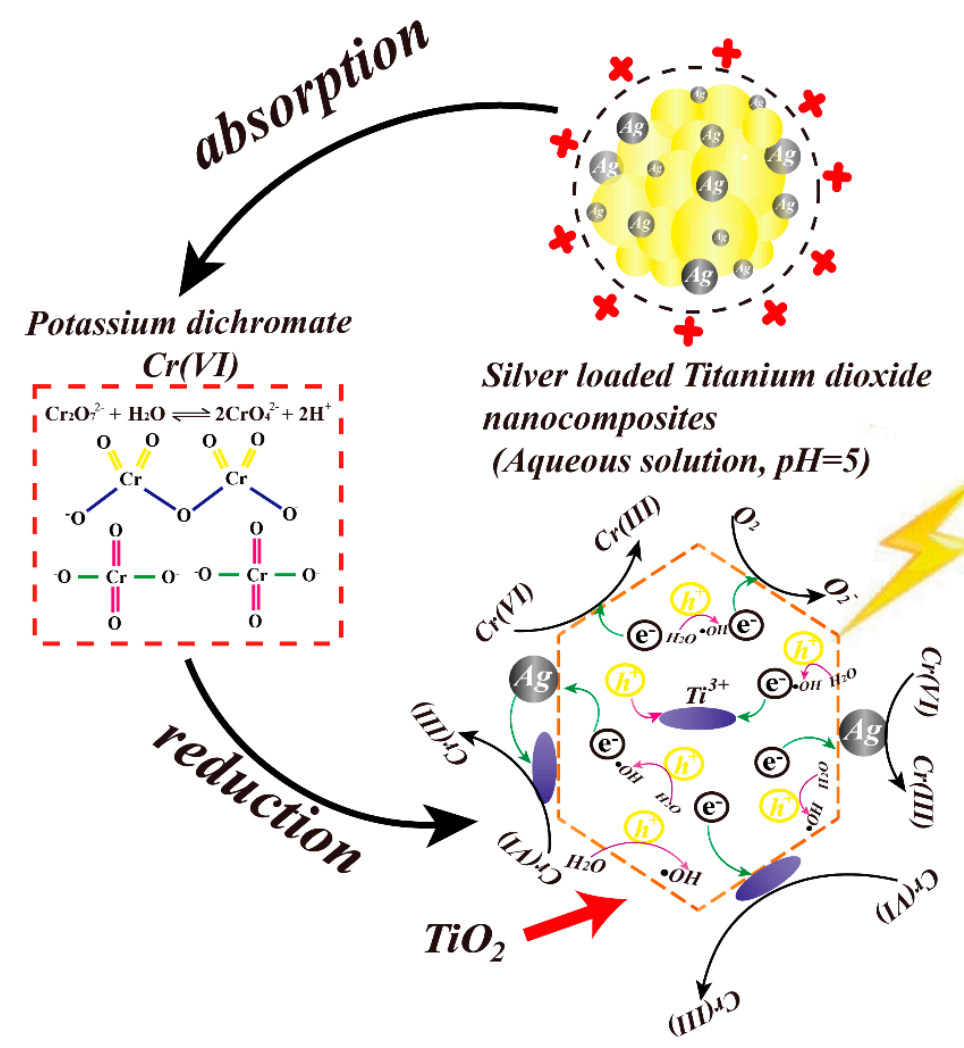

Figure 10. Mechanism of $\mathrm{Cr}(\mathrm{VI})$ photoreduction by ultra-trace $\mathrm{Ag}$ enhanced $\mathrm{TiO}_{2}$ composites. 3 . Materials and Methods.

\section{Materials and Methods}

\subsection{Materials}

Potassium dichromate $\left(\mathrm{K}_{2} \mathrm{Cr}_{2} \mathrm{O}_{7}\right)$, sodium hydroxide $(\mathrm{NaOH})$, hydrochloric acid $(\mathrm{HCl}, 36.0-38.0 \%)$ were all of analytical grade. Absolute ethanol $\left(\mathrm{C}_{2} \mathrm{H}_{5} \mathrm{OH}\right)$ was premium grade pure. All of the chemicals above were purchased from Kelong Chemical Reagent Company (Sichuan, $\mathrm{China}_{\text {). }} \mathrm{TiO}_{2}$ (P25) nanoparticles powder was supplied by Degussa Company (Essen, Germany), which is a mixture of anatase and rutile (8:2) with primary particle sizes of $20-30 \mathrm{~nm}$. Silver nitrate $\left(\mathrm{AgNO}_{3}\right)$ was obtained from Aladdin Industrial Corporation (Shanghai, China). Deionized (D.I.) water was produced by Ulupure Milli-Q water purification system.

\subsection{Preparation of Ag@TiO 2 Photocatalyst via Ultrasonic Impregnation Assisted Photoreduction Deposition}

Silver was deposited onto the surface of $\mathrm{TiO}_{2}$ formed via a "green" ultrasonic impregnation assisted photoreduction strategy. Firstly, a suspension of titanium dioxide nanoparticles (P25, 10 g/L) with absolute ethanol solution (different concentrations of ethanol solution ca. 0\%, 25\%, 50\%, 75\% and $100 \%$, as an electron donor) and a precious metal precursor solution $\left(\mathrm{AgNO}_{3} 0.074 \mathrm{mM}\right)$ were stirred and ultrasound 30 min under dark conditions. Then, the suspension was transferred to a quartz reactor under UV irradiation (300 W mercury lamp) for another $30 \mathrm{~min}$. Finally, the obtained $\mathrm{Ag} @ \mathrm{TiO}_{2}$ nanocomposites were filtered and washed with a large amount of ultrapure water to remove unreacted silver nitrate, and freeze-dried for further experiments. A typical silver loading was evaluated to be ca. 0.0648 wt $\%\left(\mathrm{Ag} / \mathrm{TiO}_{2}\right)$ by using ICP-AES (Table 1$)$. 


\subsection{Batch Experiments of Photoreduction}

The prepared photocatalyst was suspended in a quartz reactor containing $50 \mathrm{~mL}(10 \mathrm{mg} / \mathrm{L})$ target contamination $(\mathrm{Cr}(\mathrm{VI}))$. The suspension was dispersed for about $2 \mathrm{~min}$ by ultra-sonication before irradiation, and then stirred in the dark for $30 \mathrm{~min}$ to allow equilibrium adsorption of the heavy metal. A $300 \mathrm{~W}$ mercury lamp was used as a light source (irradiation about $60 \mathrm{~min}$ ) to excite $\mathrm{TiO}_{2}$ to generate photo-generated electrons and photogenerated holes to reduce heavy metals. Effects of silver load, $\mathrm{pH}$, catalyst dosage and coexisting ions on $\mathrm{Cr}(\mathrm{VI})$ reduction were fully considered. A $20 \mathrm{mg} / \mathrm{L} \mathrm{Cr}(\mathrm{VI})$ aqueous solution was diluted from $100 \mathrm{mg} / \mathrm{L} \mathrm{Cr}(\mathrm{VI})$ stock solution in $1 \mathrm{~L}$ ultra-pure water before experiments. The $\mathrm{pH}$ was monitored by PHS-320 and adjusted by $1.0 \mathrm{M} \mathrm{HCl}$ or $\mathrm{NaOH}$. The sample aliquots were intermittently $(0,10,20,30,40,50$ and $60 \mathrm{~min})$ withdrawn and filtered through a $0.45-\mu \mathrm{m}$ aqueous syringe filter for the analysis of $\mathrm{Cr}(\mathrm{VI})$ using the DPC (diphenyl-carbazide) method at $540 \mathrm{~nm}$ (UV-vis spectrophotometer).

\subsection{Catalyst Characterization and Involved Analytical Method}

The crystal structure of $\mathrm{Ag} @ \mathrm{TiO}_{2}$ was characterized by Ultima IV XRD (Rigaku Corp., Tokyo, Japan) employing $\mathrm{Cu} \mathrm{K} \alpha$ radiation $(\lambda=0.154 \mathrm{~nm}, 40 \mathrm{KV})$ in the range of $3^{\circ}$ to $80^{\circ}$. The micromorphology was observed by JEM2100 TEM (JEOL, Tokyo, Japan) operated at $200 \mathrm{kV}$. XPS measurements were performed by a K-Alpha Probe (Thermo Scientific, Waltham, MA, USA) with a monochromated Al-K $\alpha$ radiation $(300 \mathrm{~W})$. UV-vis spectra was obtained on a spectrophotometer (Shanghai United Instrument Corp., Ltd., Shanghai, China). Zeta Potential (ZP) of the nanoparticles was determined by Malvern Zeta Sizer Nano series 3600 (Malvern Instruments Ltd., Worcestershire, UK). The BET surface area was measured at $77 \mathrm{~K}$ using F-Sorb $2400 \mathrm{~N}_{2}$ adsorption analysis (Gold APP Instruments, Beijing, China).

Electron paramagnetic resonance spectra (EPR) was performed on an EMX-8 spectrometer (Bruker BioSpin Corp., Karlsruhe, Germany). First, the sample was dispersed in aqueous solution $(1 \mathrm{mg} / \mathrm{mL})$ and dispersed by ultrasonic uniformity; Second, add DMPO (100 mM) and mix well; Third, the mixed sample was placed in a flat pool, and then set in the instrument test chamber; Fourth, in situ lighting test (5 $\mathrm{min}$ ) and record the data.

Inductively coupled plasma atomic emission spectrometry (ICP-AES) was used to evaluate the Ag amount in the obtained photocatalyst by Agilent 720 (Agilent Technologies Inc., Palo Alto, CA, USA). First, $0.0164 \mathrm{~g} \mathrm{Ag@} \mathrm{TiO}_{2}$ was dissolved in aqua regia and boiled. After cooling, set it in a $50 \mathrm{~mL}$ volumetric flask. Then, dilutes the solution according to different dilution factors for detection. At last, record the data on the display. The conversion is obtained from the readings and the actual participating of samples.

\section{Conclusions}

Based on ultrasonic impregnation-assisted UV-photoreduction, $\mathrm{Ag}^{+}$could be fully reduced via a facile in-situ synthetic approach toward ultra-trace silver-doped $\mathrm{TiO}_{2}$ photocatalysts without using any reducing agents. The results demonstrated that all obtained $\mathrm{Ag} @ \mathrm{TiO}_{2}$ photocatalysts have a significant photocatalytic activity compared to commercial P25 nanoparticles in the reduction of $\mathrm{Cr}(\mathrm{VI})$, which is interpreted as the loading of Ag being used as an intermediary container for electron transfer and storage to promote the separation of photogenerated $e^{-}$and $h^{+}$. The Langmuir-Hinshelwood kinetic model can well explain the removal kinetics of $\mathrm{Cr}(\mathrm{VI})$ reduction. Regeneration performance of $\mathrm{Ag} @ \mathrm{TiO}_{2}$ indicated that the photocatalyst still maintained a rather high catalytic activity after five cycles $(62 \%)$ and could be reused. Taking the practical application of photocatalytic removal of wastewater into account, the solution $\mathrm{pH}$, coexistence of ions, dosing and other factors were considered, which will provide a useful guide for further reaction model simulation. The facile-fast, low-cost and eco-friendly method of synthesizing $\mathrm{Ag} @ \mathrm{TiO}_{2}$ nanomaterials can provide a valid strategy for 
the broad-scale preparation of precious metal matrix composites, and might be used as a promising photocatalyst for wastewater treatment.

Supplementary Materials: The following are available online at http:/ /www.mdpi.com/2073-4344/8/6/251/s1. Table S1 BET data for different silver loadings. Table S2 BET data for different solvent concentration. Table S3 XPS date of atomic (Ag@TiO $2,0.6$ wt \%). Figure S1 The Energy Dispersive Spectrdmeter of Ag@TiO 2 catalyst. Figure S2 XRD patterns of the $\mathrm{Ag} @ \mathrm{TiO}_{2}$ nanocomposites, in which $\mathrm{A}$ is anatase phase and $\mathrm{R}$ is rutile phase. Figure S3 Effect of different concentration of empty scavenger (Ethanol) on Cr reduction. Figure S4 Zeta potential of bare $\mathrm{TiO}_{2}$ and $\mathrm{Ag} @ \mathrm{TiO}_{2}$ catalyst. Figure S5 High resolution XPS of $\mathrm{Ag} 3 \mathrm{~d}$ of $\mathrm{Ag} @ \mathrm{TiO}_{2}$ catalyst before (a) and after $(b)$ reaction. Figure S6 The survey spectrum XPS spectra of the $\mathrm{Ag} @ \mathrm{TiO}_{2}$ composites.

Author Contributions: S.P., R.Z., and W.C. initiated the concept; S.P. and Y.H. designed and conceived of the experiments; Y.H. and H.C. performed the experiments; S.P., Y.H. and Z.Y. analyzed the data; H.C., R.Z., and D.D. performed the characterizations, interpreted the data; S.P. contributed reagents/materials/analysis tools; S.P., Y.H. and S.X. drafted the manuscript, W.C. and Z.D. corrected the manuscript. All authors read and approved the final manuscript.

Funding: This research received no external funding.

Acknowledgments: The authors thank Anatoly ZINCHENKO for a helpful discussion. This work was supported by the National Natural Science Foundation of China (No. 41772264) and the Research Fund of State Key Laboratory of Geohazard Prevention and Geoenvironment Protection (SKLGP2018Z006). Wei Chu.

Conflicts of Interest: The authors declare no conflict of interest.

\section{References}

1. De Flora, S.; Bagnasco, M.; Serra, D.; Zanacchi, P. Genotoxicity of chromium compounds. A review. Mutat. Res. 1990, 238, 99-172. [CrossRef]

2. Ellis, A.S.; Bullen, T.D. Chromium isotopes and the fate of hexavalent chromium in the environment. Science 2002, 295, 2060-2062. [CrossRef] [PubMed]

3. Kebir, M.; Chabani, M.; Nasrallah, N.; Bensmaili, A.; Trari, M. Coupling adsorption with photocatalysis process for the $\mathrm{Cr}(\mathrm{VI})$ removal. Desalination 2011, 270, 166-173. [CrossRef]

4. Cimino, G.; Passerini, A.; Toscano, G. Removal of toxic cations and Cr(VI) from aqueous solution by hazelnut shell. Water Res. 2000, 34, 2955-2962. [CrossRef]

5. Sheng, G.; Hu, J.; Li, H.; Li, J.; Huang, Y. Enhanced sequestration of Cr(VI) by nanoscale zero-valent iron supported on layered double hydroxide by batch and XAFS study. Chemosphere 2016, 148, 227-232. [CrossRef] [PubMed]

6. Yang, L.; Zheng, X.; Liu, M.; Luo, S.; Luo, Y.; Li, G. Fast photoelectro-reduction of Cr(VI) over $\mathrm{MoS}_{2} @ \mathrm{TiO}_{2}$ nanotubes on Ti wire. J. Hazard. Mater. 2017, 329, 230-240. [CrossRef] [PubMed]

7. Bhowal, A.; Datta, S. Studies on transport mechanism of $\mathrm{Cr}(\mathrm{VI})$ extraction from an acidic solution using liquid surfactant membranes. J. Membr. Sci. 2001, 188, 1-8. [CrossRef]

8. Chuang, S.M.; Vinh, Y.; Feng, C.L.; Lee, S.J.; Choo, K.H.; Li, C.W. Electrochemical Cr(VI) reduction using a sacrificial Fe anode: Impacts of solution chemistry and stoichiometry. Sep. Purif. Technol. 2017, 191, 167-172. [CrossRef]

9. Alowitz, M.J.; Scherer, M.M. Kinetics of nitrate, nitrite, and $\mathrm{Cr}(\mathrm{VI})$ reduction by iron metal. Environ. Sci. Technol. 2002, 36, 299-306. [CrossRef] [PubMed]

10. Pu, S.; Xiang, C.; Zhu, R.; Ma, H.; Zinchenko, A.; Chu, W. An efficient heterogeneous Fenton catalyst based on modified diatomite for degradation of cationic dye simulated wastewater. Desalin. Water Treat. 2017, 79, 378-385. [CrossRef]

11. Gheju, M.; Balcu, I. Removal of chromium from $\mathrm{Cr}(\mathrm{VI})$ polluted wastewaters by reduction with scrap iron and subsequent precipitation of resulted cations. J. Hazard. Mater. 2011, 196, 131-138. [CrossRef] [PubMed]

12. Ma, H.; Pu, S.Y.; Ma, J.; Yan, C.; Zinchenko, A.; Pei, X.J.; Chu, W. Formation of multi-layered chitosan honeycomb spheres via breath-figure-like approach in combination with co-precipitation processing. Mater. Lett. 2018, 211, 91-95. [CrossRef]

13. Hu, J.; Chen, G.; Lo, I.M. Removal and recovery of $\mathrm{Cr}(\mathrm{VI})$ from wastewater by maghemite nanoparticles. Water Res. 2005, 39, 4528-4536. [CrossRef] [PubMed]

14. Galán, B.; Castañeda, D.; Ortiz, I. Removal and recovery of $\mathrm{Cr}(\mathrm{VI})$ from polluted ground waters: A comparative study of ion-exchange technologies. Water Res. 2005, 39, 4317-4324. [CrossRef] [PubMed] 
15. Barrera, C. A review of chemical, electrochemical and biological methods for aqueous $\mathrm{Cr}(\mathrm{VI}) \mathrm{reduction}$. J. Hazard. Mater. 2012, 1, 223-224.

16. Chen, D.; Ray, A.K. Removal of toxic metal ions from wastewater by semiconductor photocatalysis. Chem. Eng. Sci. 2001, 56, 1561-1570. [CrossRef]

17. Minero, C.; Mariella, G.; Maurino, V.; Vione, A.D.; Pelizzetti, E. Photocatalytic Transformation of Organic Compounds in the Presence of Inorganic Ions. 2. Competitive Reactions of Phenol and Alcohols on a Titanium Dioxide-Fluoride System. Langmuir 2015, 16, 8964-8972. [CrossRef]

18. Zhang, Y.; Chen, Z.; Liu, S.; Xu, Y.J. Size effect induced activity enhancement and anti-photocorrosion of reduced graphene oxide/ $\mathrm{ZnO}$ composites for degradation of organic dyes and reduction of $\mathrm{Cr}(\mathrm{VI})$ in water. Appl. Catal. B 2013, 140-141, 598-607. [CrossRef]

19. Mirghani, M.; Al-Mubaiyedh, U.A.; Nasser, M.S.; Shawabkeh, R. Experimental study and modeling of photocatalytic reduction of $\mathrm{Pb} 2+$ by $\mathrm{WO}_{3} / \mathrm{TiO}_{2}$ nanoparticles. Sep. Purif. Technol. 2015, 14, $285-293$. [CrossRef]

20. Sreekantan, S.; Lai, C.W.; Zaki, S.M. The Influence of Lead Concentration on Photocatalytic Reduction of $\mathrm{Pb}$ (II) Ions Assisted by $\mathrm{Cu}-\mathrm{TiO}_{2}$ Nanotubes. Int. J. Photoenergy 2014, 2014, 839106. [CrossRef]

21. Dozzi, M.V.; Marzorati, S.; Longhi, M.; Coduri, M.; Artiglia, L.; Selli, E. Photocatalytic activity of $\mathrm{TiO}_{2}-\mathrm{WO}_{3}$ mixed oxides in relation to electron transfer efficiency. Appl. Catal. B 2016, 186, 157-165. [CrossRef]

22. Dozzi, M.V.; Saccomanni, A.; Selli, E. Cr(VI) photocatalytic reduction: Effects of simultaneous organics oxidation and of gold nanoparticles photodeposition on $\mathrm{TiO}_{2}$. J. Hazard. Mater. 2012, 99, 188-195. [CrossRef] [PubMed]

23. Matamoros-Ambrocio, M.; Ruiz-Peralta, M.; Chigo-Anota, E.; García-Serrano, J.; Pérez-Centeno, A.; Sánchez-Cantú, M.; Rubio-Rosas, E.; Escobedo-Morales, A. A Comparative Study of Gold Impregnation Methods for Obtaining Metal/Semiconductor Nanophotocatalysts: Direct Turkevich, Inverse Turkevich, and Progressive Heating Methods. Catalysts 2018, 8, 161. [CrossRef]

24. $\mathrm{Ku}, \mathrm{Y}$; J Jung, I.L. Photocatalytic reduction of $\mathrm{Cr}(\mathrm{VI})$ in aqueous solutions by UV irradiation with the presence of titanium dioxide. Water Res. 2001, 35, 135-142. [CrossRef]

25. Colón, G.; Hidalgo, M.C.; Naviío, J.A. Photocatalytic deactivation of commercial $\mathrm{TiO}_{2}$ samples during simultaneous photoreduction of $\mathrm{Cr}(\mathrm{VI})$ and photooxidation of salicylic acid. J. Photochem. Photobiol. 2001, 138, 79-85. [CrossRef]

26. Zheng, Z.; Huang, B.; Qin, X.; Zhang, X.; Dai, Y.; Whangbo, M.H. Facile in situ synthesis of visible-light plasmonic photocatalysts $\mathrm{M} @ \mathrm{TiO}_{2}(\mathrm{M}=\mathrm{Au}, \mathrm{Pt}, \mathrm{Ag})$ and evaluation of their photocatalytic oxidation of benzene to phenol. J. Mater. Chem. 2011, 21, 9079-9087. [CrossRef]

27. Cheng, B.; Le, Y.; Yu, J. Preparation and enhanced photocatalytic activity of Ag@TiO 2 core-shell nanocomposite nanowires. J. Hazard. Mater. 2010, 177, 971-977. [CrossRef] [PubMed]

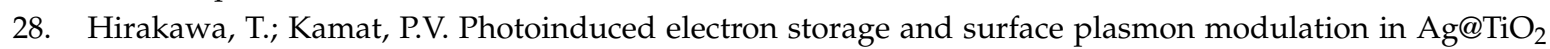
clusters. Langmuir 2004, 20, 5645-5647. [CrossRef] [PubMed]

29. Xiang, Q.; Yu, J.; Cheng, P.; Ong, H.C. Microwave-Hydrothermal Preparation and Visible-Light Photoactivity of Plasmonic Photocatalyst Ag- $\mathrm{TiO}_{2}$ Nanocomposite Hollow Spheres. Chem. Asian J. 2010, 5, 1466-1474. [CrossRef] [PubMed]

30. Zhang, $\mathrm{H}$;; Chen, G. Potent antibacterial activities of $\mathrm{Ag} / \mathrm{TiO}_{2}$ nanocomposite powders synthesized by a one-pot sol-gel method. Environ. Sci. Technol. 2009, 43, 2905-2910. [CrossRef] [PubMed]

31. Wang, Y.; Chao, Y.; Lei, C.; Zhang, Y.; Yang, J. Controllable Charge Transfer in Ag- $\mathrm{TiO}_{2}$ Composite Structure for SERS Application. Nanomaterials 2017, 7, 159. [CrossRef] [PubMed]

32. Guin, D.; Manorama, S.V.; Latha, J.N.L.; Singh, S. Photoreduction of Silver on Bare and Colloidal TiO 2 Nanoparticles/Nanotubes: Synthesis, Characterization, and Tested for Antibacterial Outcome. J. Phys. Chem. C 2007, 111, 13393-13397. [CrossRef]

33. Behnajady, M.A.; Modirshahla, N.; Shokri, M.; Rad, B. Enhancement of photocatalytic activity of $\mathrm{TiO}_{2}$ nanoparticles by Silver doping: Photodeposition versus liquid impregnation methods. Glob. NEST J. 2007, 10, 1-7.

34. Liu, L.; Liu, Z.; Bai, H.; Sun, D.D. Concurrent filtration and solar photocatalytic disinfection/degradation using high-performance $\mathrm{Ag} / \mathrm{TiO}_{2}$ nanofiber membrane. Water Res. 2012, 46, 1101-1112. [CrossRef] [PubMed] 
35. Pu, S.Y.; Hui, M.; Zinchenko, A.; Wei, C. Novel highly porous magnetic hydrogel beads composed of chitosan and sodium citrate: An effective adsorbent for the removal of heavy metals from aqueous solutions. Environ. Sci. Pollut. Res. 2017, 24,1-11. [CrossRef] [PubMed]

36. Deng, Z.; Ning, J.; Su, Z.; Xu, S.; Xing, Z.; Wang, R.; Lu, S.; Dong, J.; Zhang, B.; Yang, H. Structural Dependences of Localization and Recombination of Photogenerated Carriers in the top GaInP Subcells of GaInP/GaAs Double-Junction Tandem Solar Cells. ACS Appl. Mater. Interfaces 2015, 7, 690-695. [CrossRef] [PubMed]

37. Yang, C.K.; Wang, S.F.; Tsai, H.Y.; Lin, S.Y. Intrinsic photocatalytic oxidation of the dye adsorbed on $\mathrm{TiO}_{2}$ photocatalysts by diffuse reflectance infrared Fourier transform spectroscopy. Appl. Catal. B 2001, 30, $293-301$. [CrossRef]

38. Davis, R.J.; Gainer, J.L.; O’Neal, G.; Wu, I.W. Photocatalytic Decolorization of Wastewater Dyes. Water Environ. Res. 1994, 66, 50-53. [CrossRef]

39. Pu, S.; Wang, M.; Wang, K.; Hou, Y.; Yu, J.; Shi, Q.; Pei, X.; Chu, W. Preparation of CS-Fe@Fe $\mathrm{F}_{4}$ nanocomposite as an efficient and recyclable adsorbent for azo dyes removal. Desalin. Water Treat. 2018, 95, 319-332. [CrossRef]

40. Li, Y.; Bian, Y.; Qin, H.; Zhang, Y.; Bian, Z. Photocatalytic reduction behavior of hexavalent chromium on hydroxyl modified titanium dioxide. Appl. Catal. B 2017, 206, 293-299. [CrossRef]

41. Lei, X.F.; Xue, X.X.; Yang, H. Preparation and characterization of Ag-doped $\mathrm{TiO}_{2}$ nanomaterials and their photocatalytic reduction of $\mathrm{Cr}(\mathrm{VI})$ under visible light. Appl. Surf. Sci. 2014, 321, 396-403. [CrossRef]

42. Aguado, M.A.; GimãNez, J.; Cervera-March, S. Continuous photocatalytic treatment of Cr(VI) effluents with semiconductor powders. Chem. Eng. Commun. 1991, 104, 71-85. [CrossRef]

(C) 2018 by the authors. Licensee MDPI, Basel, Switzerland. This article is an open access article distributed under the terms and conditions of the Creative Commons Attribution (CC BY) license (http:/ / creativecommons.org/licenses/by/4.0/). 